\title{
Quantitative analysis of azaspiracids in Azadinium spinosum cultures
}

Thierry Jauffrais ${ }^{1,{ }^{*}}$, Christine Herrenknecht ${ }^{2}$, Véronique Séchet ${ }^{1}$, Manoella Sibat ${ }^{1}$, Urban Tillmann ${ }^{3}$ Bernd Krock ${ }^{3}$, Jane Kilcoyne ${ }^{4}$, Christopher O. Miles ${ }^{5}$, Pearse McCarron ${ }^{6}$, Zouher Amzil ${ }^{1}$, Philipp Hess $^{1, *}$

${ }^{1}$ IFREMER, Laboratoire EMP/PHYC. Rue de l'Ile d'Yeu. 44311 Nantes. France

2 Nantes Atlantique Université, MMS EA2160, 9 rue Bias. 44035 Nantes. France

${ }^{3}$ Alfred Wegener Institute, Am Handelshafen 12. D-27570 Bremerhaven. Germany

${ }^{4}$ Marine Institute, Rinville, Oranmore, Co. Galway, Ireland

${ }^{5}$ Norwegian Veterinary Institute, P. O. Box 750 sentrum, 0106 Oslo, Norway

${ }^{6}$ National Research Council Canada, 1411 Oxford Street, Halifax, Nova Scotia B3H 3Z1, Canada

*: Corresponding author : T. Jauffrais, email address : Thierry.Jauffrais@ifremer.fr, P. Hess, email address : Philipp.Hess@ifremer.fr

\begin{abstract}
:
Azaspiracids (AZAs) are secondary metabolites of Azadinium spinosum that can accumulate in shellfish and cause food poisoning when consumed. We describe here an analytical procedure for the determination of AZAs in cultures of $A$. spinosum with a focus on the formation of AZA methyl esters as artefacts during extraction and sample pre-treatment. $A$. spinosum cells were collected from bioreactor cultures using centrifugation or filtration. Different extraction procedures were evaluated for formation of methyl ester artefacts, yield, and matrix effects. Filtration of cultures using glass-fibre filters led to increased formation of methyl esters, and centrifugation is recommended for recovery of cells. The extraction solvent (methanol $(\mathrm{MeOH})$, acetone, and acetonitrile $(\mathrm{MeCN})$ ) did not significantly affect the yield of AZAs as long as the organic content was $80 \%$ or higher. However, the use of $\mathrm{MeOH}$ as extraction solvent led to increased formation of methyl esters. AZA1 recovery over two successive extractions was $100 \%$ at the $95 \%$ confidence level for acetone and $\mathrm{MeOH}$. In standard-addition experiments, no significant matrix effects were observed in extracts of $A$. spinosum or Azadinium obesum up to a sample size of $4.5 \times 10^{9} \mu^{3}$. Moreover, experiments carried out to clarify the formation and structure of methylated AZA analogues led to the description of two AZA methyl esters and to the correction of the chemical structures of AZAs29-32.
\end{abstract}

Keywords: Extraction procedure - Extraction artefact - Matrix effects - LC-MS/MS - Azaspiracid methyl ester - Dinoflagellate - Liquid chromatography-mass spectrometry 


\section{Introduction}

Harmful algal blooms are widespread throughout the world, frequently causing problems to public health through consumption of contaminated shellfish and, amongst these, azaspiracid shellfish poisoning is the most recently identified syndrome. In 1995, a human intoxication occurred in the Netherlands after consumption of mussels from Ireland (Killary Harbour), with symptoms typical for diarrhetic shellfish poisoning (DSP). The incident caused diarrhea, nausea, vomiting and stomach cramps in consumers; however, only very low levels of OAgroup toxins were found in mussels [1]. A new toxin named azaspiracid (AZA) (now referred to as Azaspiracid-1 (AZA1) (Fig. 1)), was identified three years later [2], with its structure being revised after synthetic studies [3]. AZAs 4-5 were subsequently isolated from contaminated mussels and their structures established using mass spectrometry and NMR spectroscopy [4,5]. Additional AZAs have since been identified and structures proposed based on mass spectrometry, and the group now comprises 32 analogues, including several hypothetical compounds and artefacts [6,7]. Since their initial discovery, AZAs have been found in Europe, Africa and more lately in America and in Japan [8-14].

Even though consumption of AZA-contaminated shellfish has caused public health problems since 1995, it was not until 2003 that AZAs were detected in plankton, namely in the dinoflagellate Protoperidinium crassipes [15]. However, a question rapidly arose over whether this organism was an actual AZA producer or whether it was a predator which accumulated the toxin from another organism [16,17]. As $P$. crassipes is a heterotrophic dinoflagellate [18] capable of accumulating phycotoxins [19], and since culturing did not result in AZA production (Tillmann and Krock, unpublished data in [20]), research focussed on possible prey of this species. During a cruise in 2007, a dinoflagellate source of AZAs (strain 3D9), was discovered [21]. This organism was found to contain AZA1 and AZA2 in the field, and produced de novo AZA1 and -2 in axenic culture $[22,20]$. The organism, a small (12-16 $\mu \mathrm{m}$ length and 7-11 $\mu \mathrm{m}$ width) peridinin-containing photosynthetic dinoflagellate with a thin theca, was formally described by Tillmann et al. [20] and named Azadinium spinosum. This species was the type-species for a new genus, and was soon joined by two non-AZAproducing species: Azadinium obesum (2E10) [23], a somewhat larger organism (13-18 $\mu \mathrm{m}$ length, 10-14 $\mu \mathrm{m}$ width); and Azadinium poporum, which is similar in size to $A$. spinosum but has a slightly lower mean cell length:width ratio (11-16 $\mu \mathrm{m}$ length and 8-12 $\mu \mathrm{m}$ width) [24]. Interestingly, since the morphological description of $A$. spinosum, strains of this organism have also been reported from Mexico [25], Argentina [26], Italy and France (personal communication, R. Siano and E. Nézan, Ifremer, France) and, as to be expected, from Ireland [27]. As the organism appears to be widespread in many oceans, and since AZAs have been reported from many locations, azaspiracid poisoning should be considered of global concern. We have therefore cultivated this organism to better understand the ecophysiology of Azadinium, its toxin production and the kinetics of AZA accumulation in shellfish. Finally, quantitative knowledge of the AZA-production by $A$. spinosum is also essential information for the sustainable production of toxins for toxicology experiments and instrument calibration.

In previous studies, the cellular quota of AZAs was highly variable, ranging from 5-40 fg.cell ${ }^{-1}$ $[20,27]$, while in our own studies we found up to $100 \mathrm{fg} \cdot \mathrm{cell}^{-1}$. Such differences may arise from differences in either culture conditions or in analytical procedures, including extraction, recovery in sample pre-treatment, or matrix effects in the final determination using liquid chromatography coupled to tandem mass spectrometry (LC-MS/MS). Consequently, studies on environmental and nutritional factors affecting $A$. spinosum growth and toxicity will require standardised analysis of cells and culture media for their toxin content. Therefore, we decided to investigate the analysis of AZAs from cultures of $A$. spinosum.

Like other lipophilic toxins, AZAs are typically extracted from phytoplankton or contaminated bivalves with organic solvents [28]. Historically, acetone has been used to extract lipophilic toxins from shellfish for the mouse bioassay, whereas $\mathrm{MeOH}$ and mixtures of $\mathrm{MeOH}$-water have been used for extraction prior to LC-MS/MS analysis $[29,16]$. These procedures result 
in crude extracts that typically cause matrix effects (signal enhancement or reduction) in LCMS/MS analysis [30]. Matrix effects have been reported in quantitation of AZAs in mussels by LC-MS/MS using different technical approaches [31], and possible solutions were proposed [32,33]. Therefore, matrix effects also need to be evaluated in analytical procedures for quantitation of AZAs in phytoplankton.

A novel AZA analogue observed by Krock et al. [22], and provisionally denoted as "AZAX", was detected in methanolic extracts of Azadinium cultures, and possessed a molecular ion corresponding to that of $A Z A 1$ methyl ester. However, the relative retention time of $A Z A X$ did not appear to match that originally reported for AZA1 methyl ester [34] (denoted as AZA30 by these authors). Therefore, clarification of the structures and mechanisms of formation of methylated AZA artefacts was required.

The determination of AZA metabolites, and the identification of artefacts formed during analytical procedures, is important for the subsequent assessment of metabolism in shellfish, other aquatic organisms, and mammalian systems. Thus, the present study describes the development of a quantitative analytical method for the determination of AZAs in cultures of A. spinosum, clarifies the structures of methylated derivatives of AZAs, and explains the formation of AZA methyl esters as artefacts from the extraction of $A$. spinosum cells with $\mathrm{MeOH}$, and of AZA methyl ketals as artefacts of storage in $\mathrm{MeOH}$.

\section{Materials and methods}

\subsection{Culture condition and cell count}

Two species of Azadinium were used: the producer of AZA1 and -2, A. spinosum (clone 3D9) and the non-AZA-producing species $A$. obesum (clone 2E10). Both strains were grown using $\mathrm{K}$ modified medium [35], without $\mathrm{NH}_{4} \mathrm{Cl}$ and with $\mathrm{Na}_{2} \mathrm{SeO}_{3}\left(10^{-8} \mathrm{M}\right)$, at $18{ }^{\circ} \mathrm{C}$ with a photon flux density of $200 \mu \mathrm{mol} . \mathrm{m}^{-2} . \mathrm{s}^{-1}$ and a photoperiod of $16 \mathrm{~h}$ of light and $8 \mathrm{~h}$ of dark, in a $2.5 \mathrm{~L}$ or $100 \mathrm{~L}$ chemostat. Algae were sampled at steady state in continuous culture. Cell densities and cellular volume were determined using a particle counter (Multisizer 3 Coulter counter, Beckman).

\subsection{Reagents}

Methanol $(\mathrm{MeOH})$, acetone, acetonitrile $(\mathrm{MeCN})$, ethanol $(\mathrm{EtOH})$, and dichloromethane (DCM) were obtained as HPLC grade solvents from JT Baker and Sigma Aldrich. Formic acid (Puriss quality), ammonium formate (Purity for MS), methanol- $\mathrm{d}_{4}(99.8 \%), \mathrm{N}$-methyl- $\mathrm{N}$ nitroso- $p$-toluenesulfonamide, di(ethylene glycol)ethyl ether and 9-anthraldehyde were obtained from Sigma-Aldrich. Milli-Q water for HPLC was produced in-house using a Milli-Q integral 3 system (Millipore).

Spiking experiments were carried out using AZA1 purified by $P$. Hess in collaboration with $M$. Satake in Japan (2001), according to published procedures [5]. AZA1 calibrants for LCMS/MS analysis were dilutions of either certified AZA1 (CRM-AZA1, National Research Council Canada (NRCC), Halifax, Canada), or using the above AZA1 purified in Japan (calibrated against CRM-AZA1).

\subsection{LC-MS/MS analysis}

The samples were analysed by LC-MS/MS using an Agilent 1100 LC coupled to a triple quadrupole mass spectrometer (API 2000, Applied Biosystems), a UFLCxr (Shimadzu) coupled to a triple quadrupole hybrid mass spectrometer Q-trap (API 4000QTRAP, Applied Biosystems), and an Agilent 1200 HPLC coupled to an Agilent 6540 QTOF instrument 
equipped with an electrospray ionization source for quantitation and accurate mass spectral analysis of AZAs.

\subsubsection{Liquid chromatography}

HPLC was carried out using BDS-Hypersil C8 $(50 \times 2 \mathrm{~mm}, 3 \mu \mathrm{m}$ and $150 \times 2.1 \mathrm{~mm}, 3 \mu \mathrm{m})$, MOS-Hyperclone C8 $(50 \times 2 \mathrm{~mm}, 3 \mu \mathrm{m})$ and Hypersil-Gold C18 $(50 \times 2 \mathrm{~mm}$ i.d., $2 \mu \mathrm{m})$ silicabased reversed phase columns (Thermo Scientific). Injection volumes were $5 \mu \mathrm{L}$. The A and B mobile phases were $100 \%$ water and acetonitrile/water $(95: 5, \mathrm{v} / \mathrm{v})$ respectively, both containing $2 \mathrm{mM}$ ammonium formate and $50 \mathrm{mM}$ formic acid.

The $50 \mathrm{~mm}$ BDS-Hypersil column was eluted isocratically at $250 \mu \mathrm{L} \cdot \mathrm{min}^{-1}(75 \% \mathrm{~B})$ at $20{ }^{\circ} \mathrm{C}$ for 5-10 min, depending on which analogues were analysed. The MOS-Hyperclone C8 column was used in gradient elution mode $\left(200 \mu \mathrm{L} \cdot \mathrm{min}^{-1}\right.$ at $\left.20^{\circ} \mathrm{C}\right)$ starting with $70 \% \mathrm{~B}$ rising to $100 \%$ B at $2.5 \mathrm{~min}$, held for $4.5 \mathrm{~min}$, decreasing to $70 \% \mathrm{~B}$ over $6 \mathrm{~min}$, and held for $5 \mathrm{~min}$ until the next run.

The $150 \mathrm{~mm}$ BDS-Hypersil C8 column was used in gradient elution mode $\left(200 \mu \mathrm{L} \cdot \mathrm{min}^{-1}\right.$ at 30 ${ }^{\circ} \mathrm{C}$ ) for acquisition of accurate mass data, starting with $25 \%$ B rising to $100 \%$ B at 12 min, held for $8 \mathrm{~min}$, decreasing to 25\% B over $1 \mathrm{~min}$, and held for 10 min until the next run.

The Hypersil Gold C18 column was eluted with a gradient for determination of AZAs and AZA ADAM derivatives, starting with $62.5 \%$ B rising to $100 \%$ B at 4 min, held for 5 min, decreasing to $62.5 \% \mathrm{~B}$ over $0.5 \mathrm{~min}$, and held for 5 min until the next run.

\subsubsection{Mass spectrometry}

Multiple reaction monitoring (MRM) and fragmentation experiments were performed in positive ion mode under the conditions given in Table 1. Selected ion monitoring (SIM) was performed in negative mode. The following MRM transitions were monitored: AZA1, $\mathrm{m} / \mathrm{z}$ $842.5 \rightarrow 824.5, \quad 842.5 \rightarrow 672.5 ; \quad$ AZA2 and AZA1 methyl ester, $m / z \quad 856.5 \rightarrow 838.5$, $856.5 \rightarrow 672.5$; AZA2 methyl ester, $m / z$ 870.5 $\rightarrow 852.5$, 870.5 $\rightarrow 672.5$; AZA1 $d_{3}$-methyl ester, $\mathrm{m} / \mathrm{z} 859.5 \rightarrow 841.5,859.5 \rightarrow 672.5 ;$ AZA2 $d_{3}$-methyl ester, $\mathrm{m} / \mathrm{z}$ 873.5 $\rightarrow 855.5,873.5 \rightarrow 672.5$; AZA1 methyl ketal (AZA30), $\mathrm{m} / \mathrm{z}$ 856.5 $\rightarrow 824.5 ; 856.5 \rightarrow 672.5 ;$ AZA2 methyl ketal (AZA32), $\mathrm{m} / \mathrm{z}$ 870.5 $\rightarrow 838.5$; 870.5 $\rightarrow 672.5$; AZA1 (9-anthryl)methyl ester, $\mathrm{m} / \mathrm{z}$ 1032.6 $\rightarrow 672.5$; AZA2 (9-anthryl)methyl ester and AZA1 methyl ketal (9-anthryl)methyl ester, $\mathrm{m} / \mathrm{z}$ 1046.6 $\rightarrow 672.5$; and AZA2 methyl ketal (9-anthryl)methyl ester, $\mathrm{m} / \mathrm{z} 1050.6 \rightarrow 672.5$. The following $[\mathrm{M}-\mathrm{H}]^{-}$ions were monitored in SIM mode: AZA1, m/z 840.5; AZA2, AZA1 methyl ester and AZA1 methyl ketal, $m / z$ 854.5; AZA2 methyl ester $m / z$ 868.5. Quantitation was carried out using external calibration against AZA1, with Analyst 1.5 software (Applied Biosystems).

Accurate mass data were acquired on an Agilent 6540 QTOF operated in positive mode, with full-scan analysis over m/z 100-1000 at 1 scan/s and targeted MS/MS analysis at 5 scans/s. Capillary and fragmentor voltages were $4000 \mathrm{~V}$ and $220 \mathrm{~V}$, respectively. The Jet Stream Technology source was set at $300{ }^{\circ} \mathrm{C}$ with a drying gas flow at $8 \mathrm{~L} / \mathrm{min}$ and a sheath gas flow of $12 \mathrm{~L} / \mathrm{min}$ at $400{ }^{\circ} \mathrm{C}$. Three collision energies $(30,50$ and $70 \mathrm{~V})$ were applied to the precursor ions to study fragmentation pathways.

Identification of AZA1 and -2 methyl esters and structure confirmation

(a) The effect of heat treatment of the filters containing $A$. spinosum samples on the formation of AZA methyl esters was tested to determine whether their formation was enzyme-catalysed. Triplicate aliquots of $A$. spinosum culture $(10 \mathrm{~mL})$ were filtered using GF/C filters and the filters (with cells) were placed in a $1.5 \mathrm{~mL}$ Eppendorf tubes. Two types of heat treatment were tested to suppress enzymatic activity: (i) microwaving for 2 min at $800 \mathrm{~W}$, or; (ii) placing in a water bath at $100{ }^{\circ} \mathrm{C}$ for $30 \mathrm{~min}$. A control, without heat treatment, was prepared in parallel. Each sample was then extracted with $\mathrm{MeOH}(5 \times 0.5 \mathrm{~mL})$ (described below). 
(b) The formation of AZA methyl esters was studied during extraction and reconstitution with $\mathrm{MeOH}$ and deuterated $\mathrm{MeOH}\left(\mathrm{CD}_{3} \mathrm{OD}\right)$. The procedure in Fig. 2 was used with the following solvents: (a) extraction with $\mathrm{MeOH}$, reconstitution with $\mathrm{MeOH}$; (b) extraction with $\mathrm{MeOH}$, reconstitution with $\mathrm{CD}_{3} \mathrm{OD}$; and (c) extraction with $\mathrm{CD}_{3} \mathrm{OD}$, reconstitution with $\mathrm{CD}_{3} \mathrm{OD}$.

(c) Treatment with diazomethane, which derivatises carboxylic acids as their methyl esters, was used to synthesise AZA1 and -2 methyl esters. A methanolic extract from $A$. spinosum $(0.5 \mathrm{~mL})$ containing AZA1 and -2 was added to the outside tube of an Aldrich diazomethane generator with System 45 connection, and $1 \mathrm{~mL} \mathrm{MeOH}$ and $1.5 \mathrm{~mL} \mathrm{Et}_{2} \mathrm{O}$ were added. Diazomethane was generated in the inner tube of the apparatus and allowed to react in situ with the extract, following the manufacturer's protocol [36]. After reacting for $45 \mathrm{~min}$ at $0{ }^{\circ} \mathrm{C}$ with occasional swirling, the extract was transferred to a glass vial, evaporated to dryness under a stream of $\mathrm{N}_{2}$, and the residue dissolved in $\mathrm{MeOH}(1 \mathrm{~mL})$ for LC-MS analysis.

(d) A sample containing AZA30 and -32 was obtained from an experiment studying storage of AZA1 and -2 standards in $\mathrm{MeOH}$ (NRCC).

(e) Samples containing AZA1 and -2 methyl esters, and AZA30, and -32 (AZA1 and -2 methyl ketals), were treated with sodium periodate as described by Rehmann et al. [7], then analysed by LC-MS/MS or by LC-MS in negative ion SIM mode. The same samples were also derivatized with 9-anthryldiazomethane, which derivatizes carboxylic acids as their (9anthryl) methyl esters, and analysed by LC-MS in positive ion MRM mode as described by McCarron et al. [37].

\subsection{Protocols for the determination of extra- and intra-cellular portion of AZAs}

Procedures for AZA extraction evaluated in this study were based on the following standard protocols.

Samples $(10 \mathrm{~mL})$ were collected from $A$. spinosum cultures and centrifuged $(2500 \mathrm{~g}, 20 \mathrm{~min}$, $4{ }^{\circ} \mathrm{C}$ ) in $15 \mathrm{~mL}$ centrifuge tubes. The culture supernatant was collected for liquid-liquid extraction as described below, and the pellet was re-suspended in $500 \mu \mathrm{L}$ of solvent and bath-sonicated (10 $\mathrm{min}$ ) after transferring to a $1.5 \mathrm{~mL}$ Eppendorf tube. After sonication, the aliquot was centrifuged $\left(15000 \mathrm{~g}, 10 \mathrm{~min}, 4^{\circ} \mathrm{C}\right)$. The supernatant was transferred to a $5 \mathrm{~mL}$ glass tube and gently evaporated under nitrogen on a heating block at $35^{\circ} \mathrm{C}$. This process was repeated so that the pellet was extracted three times in total (the number of repetitions varied as a function of the experiment, but three successive extractions were generally used) and, following evaporation of the combined supernatants from each step, the residue was reconstituted in 500 or $1000 \mu \mathrm{L} \mathrm{MeOH}-\mathrm{H}_{2} \mathrm{O}(9: 1 \mathrm{v} / \mathrm{v})$. Subsequently, the sample was filtered with a NANOSEP MF centrifugal device (PALL, $0.2 \mu \mathrm{m}, 1.5 \mathrm{~mL}$ vial with filter insert) (15000 $g, 5$ min, $4^{\circ} \mathrm{C}$ ) and transferred to an HPLC vial with insert (Fig. 2).

The supernatant from centrifugation of the algal culture was transferred to a $15 \mathrm{~mL}$ tube and $2 \mathrm{~mL}$ of DCM added. The mixture was homogenized (1 min vortexing), centrifuged (2500 $\mathrm{g}$, $10 \mathrm{~min}, 4^{\circ} \mathrm{C}$ ), and the organic phase transferred to a $15 \mathrm{~mL}$ glass tube. The supernatant was extracted three times in this manner, and the resulting DCM extract evaporated under nitrogen on a heating block at $35^{\circ} \mathrm{C}$ and the residue was reconstituted and filtered as above (Fig. 2).

The above extraction protocol was used to evaluate the following aspects of $A$. spinosum extraction:

(a) Effect of sample size, and residence time of $A$. spinosum in a $15 \mathrm{~mL}$ centrifuge tube prior analysis, on intra- an extra-cellular AZA content. The aliquots were preserved with neutral Lugol and immediately observed using a Nageotte cell-counting chamber. During the experiment, the aliquots were maintained at room temperature $\left(18 \pm 2^{\circ} \mathrm{C}\right)$.

(b) Influence of procedures for separation of algal cells from the culture medium (filtration and centrifugation) on intra- and extra-cellular AZA content.

(c) Effect of extraction solvent on yield and artefact formation.

(d) Effect of algal matrix on recovery on the standard procedure. 


\subsection{Matrix effects in LC-MS/MS analyses of culture extracts}

Matrix effects were evaluated using the following approaches:

(a) AZA1 addition to a constant amount of algal matrix. A. obesum culture medium $(10 \mathrm{~mL})$ was extracted using the standard procedure (Fig. 2) with $\mathrm{MeOH}-\mathrm{H}_{2} \mathrm{O}(9: 1)$ or acetone $-\mathrm{H}_{2} \mathrm{O}$ $(9: 1)(v / v)$. Reconstitution was carried out in triplicate using an AZA1 solution and $\mathrm{MeOH}$, to obtain AZA1 concentrations ranging from 5.3-213 ng. $\mathrm{mL}^{-1}$.

(b) The same extraction was applied as for (a) above, but with $A$. spinosum culture medium.

(c) Matrix addition to a constant AZA concentration. Samples of a culture of $A$. obesum

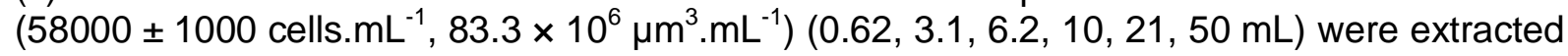
in triplicate (Fig. 2) using $\mathrm{MeOH}-\mathrm{H}_{2} \mathrm{O}(9: 1)$ or acetone- $\mathrm{H}_{2} \mathrm{O}(9: 1 \mathrm{v} / \mathrm{v})$ and reconstituted with $40 \mu \mathrm{L}$ of AZA1 solution and $460 \mu \mathrm{L}$ of $\mathrm{MeOH}-\mathrm{H}_{2} \mathrm{O}(9: 1 \mathrm{v} / \mathrm{v})$ to give an AZA1 concentration of $42.7 \mathrm{ng} \cdot \mathrm{mL}^{-1}$.

\subsection{Statistical analysis}

All data are expressed as mean \pm standard deviation. Depending on the data, statistical analyses consisted either of multifactorial analysis of variance, one-way analysis of variance (ANOVA), or a Kruskal-Wallis test, followed, when necessary, by a Fisher's least significant difference procedure or a box-and-whisker plot. Differences were considered significant at $p<0.05$. Statistical analyses were carried out using Statgraphics Centurion XV.I (StatPoint Technologies, Inc.). Before each ANOVA analysis or Kruskal-Wallis test, normality and equality of variance were tested to decide which tests were going to be used.

\section{Results and discussion}

\subsection{Identification of AZA1 and -2 methyl esters and structure confirmation}

A late-eluting LC-MS peak in A. spinosum extracts, provisionally denoted as AZAX, was previously identified as a possible isomer of AZA2 (or a methylated AZA1 analogue), based on retention time and mass $[20,21]$. The present work demonstrated the artefactual formation of methylated derivatives of AZA1 and AZA2 during extraction of $A$. spinosum cultures, and procedures that reduce their formation. However, the mechanism of formation and identities of these analogues were unclear.

Enzymatic activity can modify the chemical structure of toxins when extracting phytoplankton [38]. To test whether this might be the case for AZAs, the filters containing $A$. spinosum were heated in a water bath or microwave before extraction. Neither procedure reduced the formation of methylated analogues of AZA1 nor -2, indicating that enzymatic activity of the alga is not responsible for the formation of the methylated analogues.

Brondz et al. [39] reported that extractions of natural products with $\mathrm{MeOH}$ may produce methyl esters of fatty acids or other molecules with a carboxylic acid groups. Methyl esters of AZAs (now known to be methyl ketals, see below) have also been reported as storage artefacts [7], and the proportion of these was reduced when acetone, MeCN or DCM were used (Table 2 and 3).

To confirm that the two methylated analogues (subsequently identified as AZA1 and AZA2 methyl esters) were artefacts of the extraction/reconstitution process, and to determine at which stage formation occurred, extraction and reconstitution were carried out using $\mathrm{MeOH}$ or $\mathrm{CD}_{3} \mathrm{OD}$. The formation of methylated analogues took place mainly during extraction but also, to a lesser degree, during reconstitution (Fig. 3). Therefore, these two analogues were now clearly identified as artefacts from extraction with $\mathrm{MeOH}$, and were suspected to be AZA1 and -2 methyl esters. Methyl esters of AZA1-3 and 6, denoted as AZA29-32, were reported by Rehmann et al. and were identified as artefacts of storage in $\mathrm{MeOH}$ [7]. 
Specimens containing AZA30 and -32 as artefacts of long term storage in $\mathrm{MeOH}$ from NRCC were analysed by LC-MS/MS (Fig. 4, 5 and 6). The retention times and mass spectra (API4000, linear ion trap and Agilent 6540 QTOF) of AZA30, -32 were different to those of the two methylated AZA-extraction artefacts observed in the present study (Fig. 4 and 6). High resolution mass spectrometry was consistent with the chemical formulae of the molecular structures and fragments (Table 4 and Electronic Supplementary Material). The observation that the methylated extraction artefacts from the present study had identical retention times and mass spectra to semisynthetic AZA1 and AZA2 methyl esters (produced by treatment with diazomethane) unambiguously identified these artefacts as the methyl esters (Fig. 4 and 5).

Thus, AZA30 and -32 are methylated derivatives of AZA1 and -2 , respectively, but are not methyl esters. Rehmann et al. [7] reported an initial loss of 32 amu in the mass spectra of AZA30 and -32 , suggesting the loss of $\mathrm{MeOH}$. However, we observed only initial loss of 18 amu $\left(\mathrm{H}_{2} \mathrm{O}\right)$ in the mass spectra of authentic AZA1 and -2 methyl esters (Table 4 and Electronic Supplementary Material). A plausible hypothesis is that AZA30 and -32 are 21methyl ketals formed by exchange at the $21-\mathrm{OH}$ hemi ketal of AZA1 and AZA2, respectively, with $\mathrm{MeOH}$. This proposal is consistent with the observed initial losses of $\mathrm{H}_{2} \mathrm{O}$ from AZA1 and -2 and their methyl esters, and of $\mathrm{CH}_{3} \mathrm{OH}$ from the corresponding methyl ketals (Fig. 4 and 7 ). To test this hypothesis, samples containing AZA1 and -2 , their methyl esters, and AZA30 and -32 were treated with periodate, which oxidatively cleaves the 20,21-diol in AZAs to form a lactone derivative (Fig. 7) under mild conditions $[7,40]$. LC-MS/MS analysis showed complete conversion of AZA1 and -2 , and of their methyl esters, to the lactone, whereas no detectable reaction occurred with AZA30 and -32 , indicating that the latter compounds have been modified in the 20,21-diol moiety (Fig. 7).

LC-MS analysis in negative ion SIM mode [5] established the presence of a free carboxyl in AZA30 and -32, and the absence of a free carboxyl in AZA1 and -2 methyl esters. Only AZAs with free carboxylic acid groups would be negatively ionised in electrospray MS, and it was found that no signal was obtained for AZA1 and -2 methyl esters, while AZA1, -2, -30 and -32 were detected (Electronic Supplementary Material). Additionally, derivatization with ADAM produced (9-anthryl)methyl ester derivatives of AZA1, -2, -30 and -32 (yields $>98 \%$ ), whereas the methyl esters of AZA1 and AZA2 were unaffected (Fig. 1 and Electronic Supplementary Material). These results strongly support the hypothesis that AZA30 and -32 are the methyl ketals of AZA1 and -2, respectively, and are not methyl esters as originally reported by Rehmann et al. [7], and it seems likely that this is also the case for AZA29 and -31 (reported as methyl esters of AZA3 and -6 by Rehmann et al. [7]). The methylation artefacts from extraction of $A$. spinosum cultures are unambiguously identified as AZA1 and AZA2 methyl esters, and the "AZAX" observed in methanolic extracts by Krock et al. [22] appears to be confirmed as AZA1 methyl ester ("AZAX" mass spectrum observed by Krock et al. is presented in the Electronic Supplementary Material).

\subsection{Evaluation of extraction protocols of azaspiracid from $A$. spinosum}

\subsubsection{Particulate and dissolved toxins}

After the aliquots were sampled from the bioreactor, intra- and extra-cellular toxin contents were determined in triplicate immediately or after resting periods, with different solvents, with an aliquot of culture $(10 \mathrm{~mL})$ taken to assess morphological changes for each of the resting periods.

In laboratory culture, AZAs produced by $A$. spinosum were clearly intra-cellular. When cells were gently separated from the culture medium either by filtration or centrifugation (no cells were detected under the inverted microscope in the filtrate or supernatant), the majority of toxins were found in the particulate fraction (95\%). A significant loss of intra-cellular AZAs, with a concomitant increase in extra-cellular AZAs, was observed with increasing time between sampling and centrifugation. Apparently, increased residence time of cells in medium outside the bioreactor led to handling stress of the cells, which in turn resulted in a 
substantial loss of cell bound toxins to the dissolved phase (Electronic Supplementary Material). A significant loss of intra-cellular toxins (>10\%) occurred when cells were stressed for more than 60 min and a maximum proportion of extra-cellular toxins of $24 \%$ was observed after $5 \mathrm{~h}$. Therefore, it is recommended that samples are centrifuged immediately when the cell quota of AZAs is being determined.

Microscopical observation showed that, under these stress conditions, an increasing number of cells without theca occurred, although cells generally kept their integrity (Electronic Supplementary Material). It is a common reaction among dinoflagellates to adverse conditions that cells leave their theca (ecdysis), and is often connected with the formation of temporary cysts [41]. This type of dinoflagellate cyst normally is round and surrounded by a cell wall. However, this has not yet been observed for $A$. spinosum. The reason for the increase in extra-cellular toxins is not clear; shedding of the cells outer layer including thecal plates and their membrane vesicles might be associated with a pulsed toxin loss or extruded protoplasts may have a higher exudation rate. However, the possibility that total disintegration of a small portion of the cells contributed to the increase of extra-cellular toxins cannot be excluded.

\subsubsection{Effect of centrifugation and filtration on toxin recovery and profile}

An initial experiment was carried out in triplicate with $\mathrm{MeOH}$ as extraction solvent to evaluate AZA yield after filtration of $10 \mathrm{~mL}$ of $A$. spinosum culture on GF/C glass microfiber filters (25 mm diameter), or after centrifugation $\left(2500 \mathrm{~g}, 4{ }^{\circ} \mathrm{C}, 20 \mathrm{~min}\right)$. Both filtrate and supernatant were kept for liquid-liquid extraction with DCM (Fig. 2). Five successive extractions were carried out on each filter or pellet, to ensure complete toxin recovery. A second trial was carried out under the same conditions using either $\mathrm{MeOH}$ or acetone as extraction solvent using three successive extractions.

The total amount of AZAs obtained after 5 successive extractions using $\mathrm{MeOH}$ was not significantly different when using either filtration or centrifugation as a method to separate cells from culture medium. If only three extractions with either $\mathrm{MeOH}$ or acetone were carried out, the yield was significantly lower $(P<0.05)$ when using filtration. Moreover, the AZA ratios were different for filtration compared to centrifugation (Table 2). High levels of AZA1 and -2 methyl esters were obtained with filtration. Glass microfiber filters contain silica and are known to catalyse some reactions, which may possibly explain the methylation of AZA1 and 2 observed in these experiments. If filtration is necessary, it is recommended to study other types of filters with $A$. spinosum (i.e. polycarbonate filters).

\subsubsection{Influence of extraction solvent composition}

To determine the procedure with the best extraction yield and minimal formation of artefacts (methylated AZAs), the extraction procedure described in Fig. 2 was applied using a variety of solvents and solvent compositions. Four experiments were carried out: (a) $100 \% \mathrm{MeOH}$, acetone, $\mathrm{MeCN}, \mathrm{EtOH}$, or DCM, (b) $\mathrm{MeOH}-\mathrm{H}_{2} \mathrm{O}, 10: 0,9: 1,8: 2,7: 3,6: 4$ (v/v), (c) Acetone$\mathrm{H}_{2} \mathrm{O}, 10: 0,9: 1,8: 2,7: 3(\mathrm{v} / \mathrm{v})$, (d) $\mathrm{MeCN}-\mathrm{H}_{2} \mathrm{O}$, Acetone- $\mathrm{H}_{2} \mathrm{O}, \mathrm{MeOH}-\mathrm{H}_{2} \mathrm{O},(10: 0,9: 1(\mathrm{v} / \mathrm{v})$ each).

Between $\mathrm{MeOH}$, acetone, $\mathrm{MeCN}, \mathrm{EtOH}$ and $\mathrm{DCM}$, no significant differences were observed on AZA1, AZA2 and total AZA contents. Nonetheless, significant differences were observed in the content of AZA1 methyl ester (Table 3), with increased formation of this derivative when extracting with $\mathrm{MeOH}$ or $\mathrm{EtOH}$ (in the following order $\mathrm{MeOH}=\mathrm{EtOH}>$ acetone $>$ $\mathrm{MeCN}>\mathrm{DCM}$ ). No ethyl analogue was observed when extracting with $\mathrm{EtOH}$. It is not entirely clear how this methyl analogue formation occurs.

The formation of the methyl esters of AZA1 and -2 was variable from one experiment to the next and concentrations of AZA1 methyl ester may range from 3 to 15\% (Table 2, 3, and data not shown) when using $\mathrm{MeOH}$ as extraction solvent and centrifugation as separation technique. 
As expected, the formation of AZA1 methyl ester is significantly reduced when extracting with acetone, MeCN and DCM, however, detectable traces are still formed with these solvents used in extraction. This observation led us to hypothesize that reconstitution in $\mathrm{MeOH}$ by itself may lead to formation of AZA methyl esters. This hypothesis has been confirmed using deuterated $\mathrm{MeOH}$ (see previous section).

It is common to add some water to an organic solvent to increase the extraction yield or to minimise the extraction of lipids which could lead to matrix effects [29]. However, in the present study, no statistical differences were observed between 100,90 and $80 \% \mathrm{MeOH}$ or acetone. Nonetheless, below a ratio of $7: 3$ organic solvent $-\mathrm{H}_{2} \mathrm{O}$, the yield decreased and was significantly lower than with $\mathrm{MeOH}$.

Extraction with acetone was considered to be most appropriate, as it reduces the formation of AZA methyl esters and is easier to handle thanks to its ease of evaporation and low toxicity. However, acetone extracts may also result in more complex crude extracts, as acetone is a good solvent for extracting lipids and pigments [42]. This was an additional reason to evaluate matrix effects in further trials.

\subsubsection{Effect of sample size}

The effect of sample size on the extraction yield was studied following the standard extraction procedure (Fig. 2) using acetone- $\mathrm{H}_{2} \mathrm{O}(9: 1 \mathrm{v} / \mathrm{v})$ as extraction solvent. The $A$. spinosum culture used for this experiment had a cell concentration of $161000 \pm 1000$ cells. $\mathrm{mL}^{-1}$, corresponding to a biovolume of $92.6 \times 10^{6} \mu \mathrm{m}^{3} \cdot \mathrm{mL}^{-1}$. The following sample volumes were used: $0.62,3.1,6.2,10,31,50 \mathrm{~mL}$.

The extraction yield differed significantly as a function of sample size. Yields were somewhat higher in the middle of the studied range (3.1-31 mL). More extraction cycles or higher solvent-to-sample ratios could potentially be used to increase AZA yield for the large sample size $(50 \mathrm{~mL})$. However, the procedure was not suitable for small amounts of biomass $(<1-$ $2 \mathrm{~mL}$ ), potentially reflecting that small losses become significant when handling low amounts of toxin. Alternative protocols may need to be developed for samples below 200000 cells, such as the procedure described during the identification of $A$. spinosum [20].

\subsubsection{Recovery and yield after successive extractions in presence or absence of matrix}

Extraction yield and recovery were tested following the standard procedure with one to five successive extractions with either $\mathrm{MeOH}-\mathrm{H}_{2} \mathrm{O}$ or acetone- $\mathrm{H}_{2} \mathrm{O}(9: 1 \mathrm{v} / \mathrm{v})$, with or without matrix as follows:

(a) without matrix: AZA1 $(40 \mu \mathrm{L})$ solution $\left(0.53 \mu \mathrm{g} \cdot \mathrm{mL}^{-1}\right)$ was transferred into $15 \mathrm{~mL}$ centrifuge tubes, and extracted with $500 \mu \mathrm{L}$ of organic solvent water mixtures. The extract was reconstituted in $500 \mu \mathrm{L} \mathrm{MeOH}-\mathrm{H}_{2} \mathrm{O}(9: 1 \mathrm{v} / \mathrm{v})$. A control in triplicate with $40 \mu \mathrm{L}$ of AZA1 solution and $460 \mu \mathrm{L}$ of $\mathrm{MeOH}-\mathrm{H}_{2} \mathrm{O}(9 / 1 \mathrm{v} / \mathrm{v})$ was used to estimate the recovery.

(b) with algal matrix: Aliquots $(10 \mathrm{~mL})$ of $A$. obesum culture $\left(50000 \pm 2000\right.$ cells. $\mathrm{mL}^{-1}$, $65.2 \times 10^{6} \mu \mathrm{m}^{3} \cdot \mathrm{mL}^{-1}$ ) were centrifuged in $15 \mathrm{~mL}$ centrifuge tubes. After decanting the supernatant, AZA1 $(40 \mu \mathrm{L})$ solution was added to the pellet, extracted as described above. The extract was reconstituted in $500 \mu \mathrm{L} \mathrm{MeOH}-\mathrm{H}_{2} \mathrm{O}(9: 1 \mathrm{v} / \mathrm{v})$. For controls, A. obesum culture $(10 \mathrm{~mL})$ was extracted using $\mathrm{MeOH}-\mathrm{H}_{2} \mathrm{O}$ or acetone- $\mathrm{H}_{2} \mathrm{O}(9: 1 \mathrm{v} / \mathrm{v})$ in triplicate (Fig. 2). The control extracts were evaporated to dryness and subsequently taken up with $460 \mu \mathrm{L}$ $\mathrm{MeOH}-\mathrm{H}_{2} \mathrm{O}(9: 1 \mathrm{v} / \mathrm{v})$ and $40 \mu \mathrm{L}$ of AZA1 solution.

Two successive extractions were sufficient in all cases (100\% of recovery at $95 \%$ confidence level) while three consecutive extractions reduced the deviations observed for triplicate samples. The presence of matrix did influence recovery. Without matrix, one extraction was almost sufficient to recover all AZA, whereas two successive extractions were necessary when $A$. obesum matrix was present. No significant differences were observed between acetone and $\mathrm{MeOH}$ on AZA recovery in the presence, or absence, of matrix when two or three successive extraction cycles were carried out. 


\subsection{Evaluation of matrix effects on LC-MS/MS analysis}

Matrix effects were assessed for AZA1 using $\mathrm{MeOH}$ and acetone extracts of $A$. obesum (Fig. 8a and b, respectively), applying the standard addition method as described in Fux et al. [31]. Negligible effect (+1.4\%) was observed when using $\mathrm{MeOH}$, and more significant signal suppression $(-8.4 \%)$ was observed with acetone. For $A$. spinosum, suppression effects of $-7.7 \%$ and $-6.4 \%$ were measured for $\mathrm{MeOH}$ and acetone extracts, respectively (Fig. 8c and d).

Following the approach used by Fux et al. (28) matrix effects were also assessed by varying matrix strength while maintaining a constant AZA1 concentration (Fig. 8e). No significant matrix effects were detected with different amounts of biomass, as all values measured were within the precision of the experiment.

Previously, matrix effects were considered significant at values greater than $10 \%$ enhancement or suppression [31,43], due to the repeatability of an analytical method with LC-MS/MS. Following this arbitrary limit of significance, the effects observed here for $A$. spinosum analysis can be considered insignificant. It should be stressed that the analysis of AZAs from $A$. spinosum at this scale typically deals with much less matrix content compared to shellfish. From large-scale extraction experiments (data not shown), it is estimated that the strongest matrix crude extract using $\mathrm{MeOH}$ in our study contained ca. $2 \mathrm{mg} \cdot \mathrm{mL}^{-1}$, which is at the lowest value of the range evaluated for a shellfish matrix by Fux et al., [31].

\section{Conclusion}

These results highlight the importance of carefully studying sample preparation, extraction procedures and solvent choice for assessing the recovery of the method and possible matrix effects.

Based on the results of this study, the following procedures are recommended for the analysis of AZA-1 and -2 in A. spinosum:

Sample and immediately separate the cells from the culture medium by centrifugation.

- Extract AZAs with acetone or MeCN; acetone is most appropriate as it reduces both the formation of methyl analogues and is easy to handle thanks to its ease of evaporation and low toxicity. $\mathrm{MeOH}$ is inappropriate due to possible artefact formation.

- Two to three successive extractions are suggested to ensure high extraction yield.

- No significant matrix effects were observed during LC-MS/MS analysis with acetone or $\mathrm{MeOH}$ under the conditions tested.

This work clarifies the formation of AZA artefacts during extraction of $A$. spinosum, describes mass spectral fragmentation of two AZA methyl esters, and corrects the chemical structures of AZA29-32. Furthermore, the procedure developed allows quantitation of AZAs in algal cultures and thus will facilitate the optimisation of processes aimed at the preparative isolation of AZAs required for the sustainable supply of AZAs for instrument calibration. 


\section{Acknowledgements}

This study was carried out under the Sea Change strategy with the support of the Marine Institute and the Marine Research Sub-Programme of the National Development Plan 20072013, co-financed by the European Regional Development Fund. Further funding was obtained through Ifremer from the French Ministry of Education, Research and Technology through Programme 187 of the National Finance Law. The authors would like to thank John Lee and Dr. Thomas Glauner of Agilent Technologies for their collaboration on Q-TOF Technology. The authors would also like to thank all the members of the laboratory EMP/PHYC at the Atlantic Centre of Ifremer for their help and technical advice during this study.

\section{References}

1. McMahon T, Silke J (1996) West coast of Ireland winter toxicity of unknown aetiology in mussels. Harmful Algae News 14:2

2. Satake M, Ofuji K, Naoki H, James KJ, Furey A, McMahon T, Silke J, Yasumoto T (1998) Azaspiracid, a new marine toxin having unique spiro ring assemblies, isolated from Irish mussels, Mytilus edulis. J Am Chem Soc 120:9967-9968

3. Nicolaou KC, Koftis TV, Vyskocil S, Petrovic G, Tang WJ, Frederick MO, Chen DYK, Li YW, Ling TT, Yamada YMA (2006) Total synthesis and structural elucidation of azaspiracid1. Final assignment and total synthesis of the correct structure of azaspiracid-1. J Am Chem Soc 128:2859-2872

4. Ofuji K, Satake M, McMahon T, James KJ, Naoki H, Oshima Y, Yasumoto T (2001) Structures of azaspiracid analogs, azaspiracid-4 and azaspiracid-5, causative toxins of azaspiracid poisoning in Europe. Biosci Biotechnol Biochem 65:740-742

5. Ofuji K, Satake M, McMahon T, Silke J, James KJ, Naoki H, Oshima Y, Yasumoto T (1999) Two analogs of azaspiracid isolated from mussels, Mytilus edulis, involved in human intoxication in Ireland. Nat. Toxins 7:99-102

6. James KJ, Sierra MD, Lehane M, Magdalena AB, Furey A (2003) Detection of five new hydroxyl analogues of azaspiracids in shellfish using multiple tandem mass spectrometry. Toxicon 41:277-283

7. Rehmann N, Hess P, Quilliam MA (2008) Discovery of new analogs of the marine biotoxin azaspiracid in blue mussels (Mytilus edulis) by ultra-performance liquid chromatography/tandem mass spectrometry. Rapid Commun Mass Spectrom 22:549-558

8. Amzil Z, Sibat M, Royer F, Savar V (2008) First report on azaspiracid and yessotoxin groups detection in French shellfish. Toxicon 52:39-48

9. Furey A, O'Doherty S, O'Callaghan K, Lehane M, James KJ (2010) Azaspiracid poisoning (AZP) toxins in shellfish: Toxicological and health considerations. Toxicon 56:173-190

10. Ueoka R, Ito A, Izumikawa M, Maeda S, Takagi M, Shin-Ya K, Yoshida M, van Soest RWM, Matsunaga S (2009) Isolation of azaspiracid-2 from a marine sponge Echinoclathria sp as a potent cytotoxin. Toxicon 53:680-684

11. Magdalena AB, Lehane M, Krys S, Fernandez ML, Furey A, James KJ (2003) The first identification of azaspiracids in shellfish from France and Spain. Toxicon 42:105-108

12. Alvarez G, Uribe E, Avalos P, Marino C, Blanco J (2010) First identification of azaspiracid and spirolides in Mesodesma donacium and Mulinia edulis from Northern Chile. Toxicon 55:638-641

13. Taleb H, Vale P, Amanhir R, Benhadouch A, Sagou R, Chafik A (2006) First detection of azaspiracids in mussels in north west Africa. Journal of Shellfish Research 25:1067-1070

14. Twiner MJ, Rehmann N, Hess P, Doucette GJ (2008) Azaspiracid shellfish poisoning: A review on the chemistry, ecology, and toxicology with an emphasis on human health impacts. Marine Drugs 6:39-72 
15. James KJ, Moroney C, Roden C, Satake M, Yasumoto T, Lehane M, Furey A (2003) Ubiquitous 'benign' alga emerges as the cause of shellfish contamination responsible for the human toxic syndrome, azaspiracid poisoning. Toxicon 41:145-151

16. Hess P, Nguyen L, Aasen J, Keogh M, Kilcoyne J, McCarron P, Aune T (2005) Tissue distribution, effects of cooking and parameters affecting the extraction of azaspiracids from mussels, Mytilus edulis, prior to analysis by liquid chromatography coupled to mass spectrometry. Toxicon 46:62-71

17. Miles CO, Wilkins AL, Samdal IA, Sandvik M, Petersen D, Quilliam MA, Naustvoll LJ, Rundberget T, Torgersen T, Hovgaard P, Jensen DJ, Cooney JM (2004) A novel pectenotoxin, PTX-12, in Dinophysis spp. and shellfish from Norway. Chem Res Toxicol $17: 1423-1433$

18. Gribble KE, Anderson DM (2006) Molecular phylogeny of the heterotrophic dinoflagellates, Protoperidinium, Diplopsalis and Preperidinium (Dinophyceae), inferred from large subunit rDNA. J Phycol 42:1081-1095

19. Miles CO, Wilkins AL, Munday R, Dines MH, Hawkes AD, Briggs LR, Sandvik M, Jensen DJ, Cooney JM, Holland PT, Quilliam MA, MacKenzie AL, Beuzenberg V, Towers NR (2004) Isolation of pectenotoxin-2 from Dinophysis acuta and its conversion to pectenotoxin-2 seco acid, and preliminary assessment of their acute toxicities. Toxicon 43:1-9

20. Tillmann U, Elbrachter M, Krock B, John U, Cembella A (2009) Azadinium spinosum gen. et sp nov (Dinophyceae) identified as a primary producer of azaspiracid toxins. Eur J Phycol 44:63-79

21. Krock B, Tillmann U, John U, Cembella A (2008) LC-MS-MS aboard ship: tandem mass spectrometry in the search for phycotoxins and novel toxigenic plankton from the North Sea. Anal Bioanal Chem 392:797-803

22. Krock B, Tillmann U, John U, Cembella AD (2009) Characterization of azaspiracids in plankton size-fractions and isolation of an azaspiracid-producing dinoflagellate from the North Sea. Harmful Algae 8:254-263

23. Tillmann U, Elbrachter M, John U, Krock B, Cembella A (2010) Azadinium obesum (Dinophyceae), a new nontoxic species in the genus that can produce azaspiracid toxins. Phycologia 49:169-182

24. Tillmann U, Elbrachter M, John U, Krock B (2011) A new non-toxic species in the dinoflagellate genus Azadinium: A. poporum sp. nov. Eur J Phycol 46:74-87

25. Hernandez-Becerril DU, Escobae-Morales, S., Morreno-Gutiérez, SP, Baron-Campis, SA (2010) Two new records of potentially toxic phytoplankton species from the Mexican Pacific. Abstract book of the 14th International conference on harmful algae, Hersonissos: 137

26. Akselman R, Negri MR (2010) Azadinium spinosum Elbrätchter et Tillmann (Dinophyceae) is present and also caused blooms at the south western Atlantic. Abstract book of the 14th International conference on harmful algae, Hersonissos: 132

27. Salas R, Tillmann U, John U, Kilcoyne J, Burson A, Cantwell C, Hess P, Jauffrais T, Silke $\mathrm{J}$ (2011) The role of Azadinium spinosum (Dinophyceae) in the production of azaspiracid shellfish poisoning in mussels. Harmful Algae 10:774-783

28. Quilliam MA (2003) In: Hallegraef GM, Anderson DM, Cembella AD (eds) Manual on harmful marine microalgae. UNESCO, Saint-Berthevin

29. McNabb P, Selwood AI, Holland PT (2005) Multiresidue method for determination of algal toxins in shellfish: Single-laboratory validation and interlaboratory study. J AOAC Int 88:761772

30. King R, Bonfiglio R, Fernandez-Metzler C, Miller-Stein C, Olah T (2000) Mechanistic investigation of ionization suppression in electrospray ionization. J Am Soc Mass Spectrom 11:942-950

31. Fux E, Rode D, Bire R, Hess P (2008) Approaches to the evaluation of matrix effects in the liquid chromatography-mass spectrometry (LC-MS) analysis of three regulated lipophilic toxin groups in mussel matrix (Mytilus edulis). Food Addit Contam Part A 25:1024-1032

32. Kilcoyne J, Fux E (2010) Strategies for the elimination of matrix effects in the liquid chromatography tandem mass spectrometry analysis of the lipophilic toxins okadaic acid and azaspiracid-1 in molluscan shellfish. J Chromatogr A 1217:7123-7130 
33. McCarron P, Giddings SD, Quilliam MA (2011) A mussel tissue certified reference material for multiple phycotoxins. Part 2: liquid chromatography-mass spectrometry, sample extraction and quantitation procedures. Anal Bioanal Chem 400:835-846

34. Rehmann N (2008) Preparative isolation and purification of azaspiracids and related toxins from blue mussels and characterisation of new toxin analogs. PhD thesis, University College Dublin, Dublin

35. Keller MD, Selvin RC, Claus W, Guillard RRL (1987) Media for the culture of oceanic ultraphytoplankton. J Phycol 23:633-638

36. Sigma-Aldrich (2007) Technical Bulletin AL-180: Diazald and Diazomethane Generators, $6 \mathrm{pp}$.

http://www.sigmaaldrich.com/etc/medialib/docs/Aldrich/Bulletin/al_techbull_al180.Par.0001.Fi le.tmp/al techbull al180.pdf. Accessed 25 July 2011

37. McCarron P, Giddings SD, Miles CO, Quilliam MA (2011) Derivatization of azaspiracid biotoxins for analysis by liquid chromatography with fluorescence detection. J Chromatogr $A$ 1218:8089-8096

38. Quilliam MA, Hardstaff WR, Ishida N, MacLachlan JL, Reeves AR, Ross NW, Windust AJ (1996) In: T. Yasumoto YO, and Y. Fukuyo, (ed) Harmful and Toxic Algal Blooms. UNESCO \& Tohoku University, Sendai

39. Brondz I, Ekeberg D, Hoiland K, Bell DS, Annino AR (2007) The real nature of the indole alkaloids in Cortinarius infractus: Evaluation of artifact formation through solvent extraction method development. J Chromatogr A 1148:1-7

40. McCarron P, Kilcoyne J, Miles CO, Hess P (2009) Formation of azaspiracids-3, -4, -6, and -9 via decarboxylation of carboxyazaspiracid metabolites from shellfish. J Agric Food Chem 57:160-169

41. Pfiester LA, Anderson DM (1987) In: Taylor FJR (ed) The biology of dinoflagellates, Botanical monograph vol21. Blackwell, Oxford

42. Lorenzen CJ (1967) Determination of chlorophyll and pheo-pigments - spectrographic equations. Limnol and Oceanogr 12:343-346

43. Fux E (2008) Development and evaluation of passive sampling and LC-MS based techniques for the detection and monitoring of lipophilic marine toxins in mesocosm and field studies. PhD thesis, Dublin Institute of Technology 


\section{Figures}

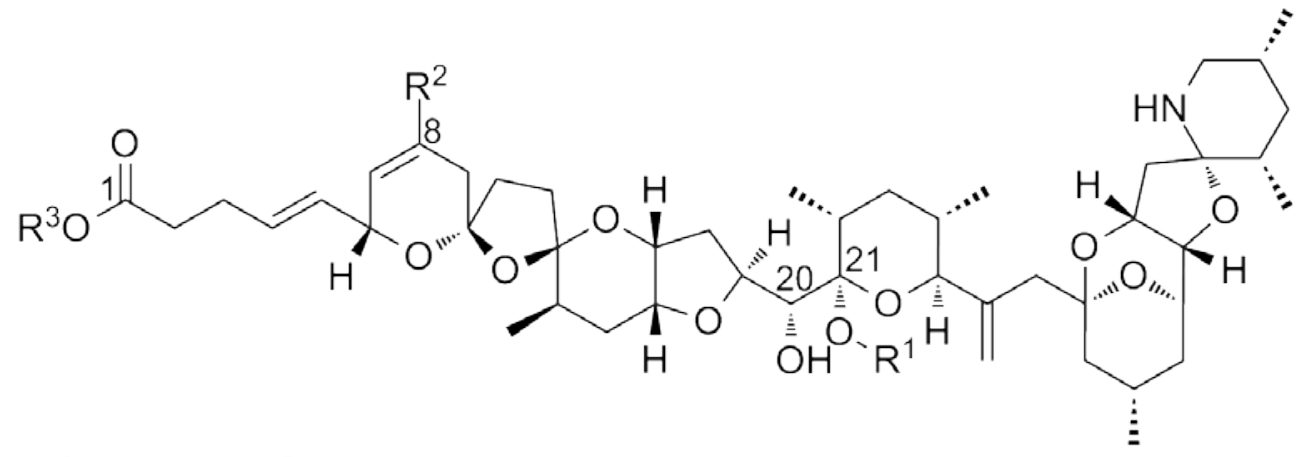

\begin{tabular}{|c|c|c|c|}
\hline $\mathrm{R}^{1}$ & $\mathrm{R}^{2}$ & $\mathrm{R}^{3}$ & Compound Name \\
\hline $\mathrm{H}$ & $\mathrm{H}$ & $\mathrm{H}$ & AZA1 \\
\hline $\mathrm{H}$ & $\mathrm{CH}_{3}$ & $\mathrm{H}$ & AZA2 \\
\hline $\mathrm{H}$ & $\mathrm{H}$ & $\mathrm{CH}_{3}$ & AZA1 methyl ester ("AZAX") \\
\hline $\mathrm{H}$ & $\mathrm{CH}_{3}$ & $\mathrm{CH}_{3}$ & AZA2 methyl ester \\
\hline $\mathrm{CH}_{3}$ & $\mathrm{H}$ & $\mathrm{H}$ & AZA1 methyl ketal ("AZA30") \\
\hline $\mathrm{CH}_{3}$ & $\mathrm{CH}_{3}$ & & AZA2 methyl ketal ("AZA32") \\
\hline $\mathrm{H}$ & & (9-anthryl)methyl & AZA1 (9-anthryl)methyl ester \\
\hline $\mathrm{H}$ & $\mathrm{CH}_{3}$ & (9-anthryl)methyl & AZA2 (9-anthryl)methyl ester \\
\hline
\end{tabular}

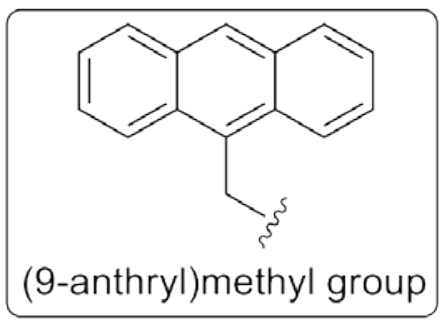

Fig. 1 Structures of AZA1, -2 and their methyl and (9-anthryl)methyl derivatives 


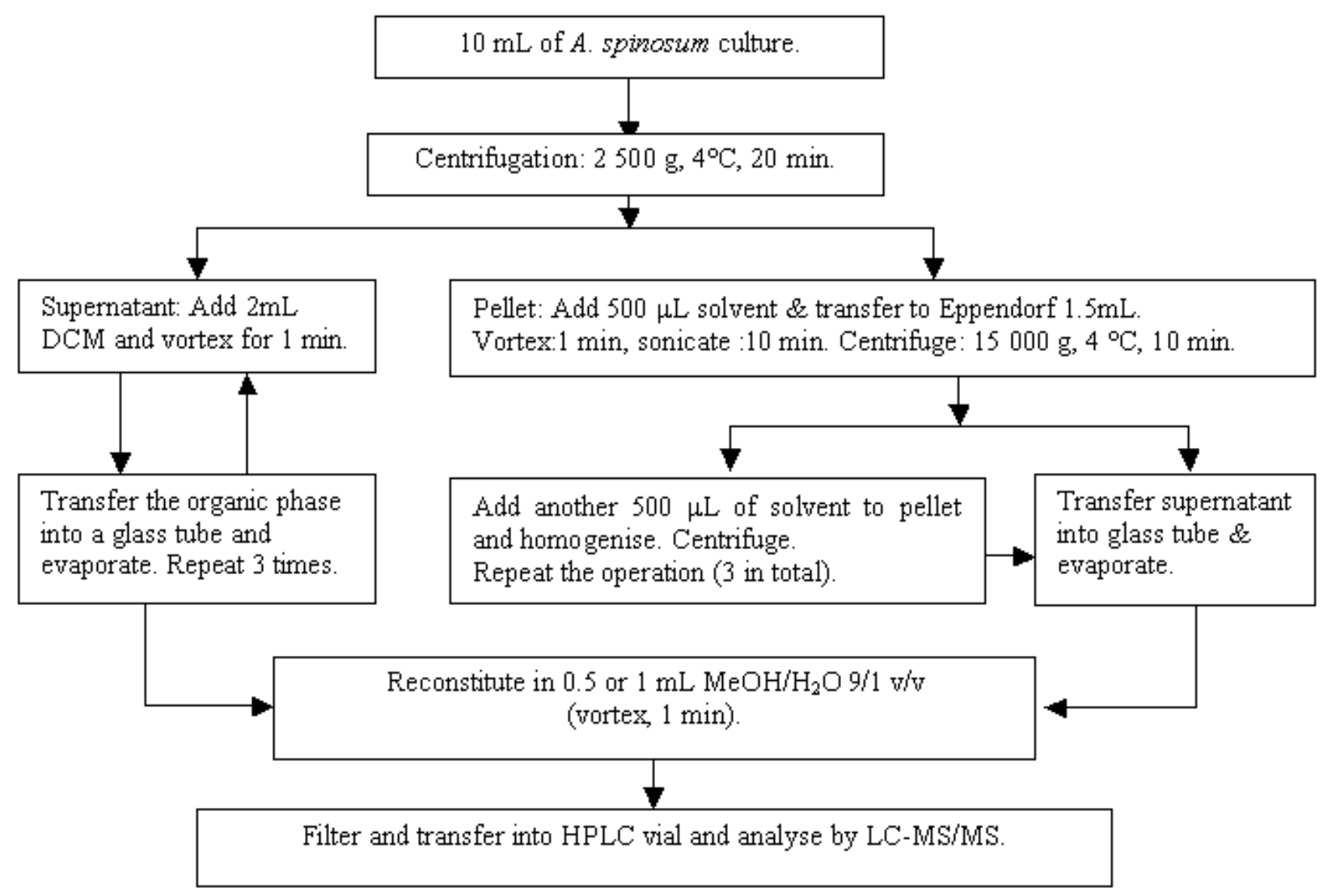

Fig. 2 Sample preparation scheme for extraction of AZAs from A. spinosum 


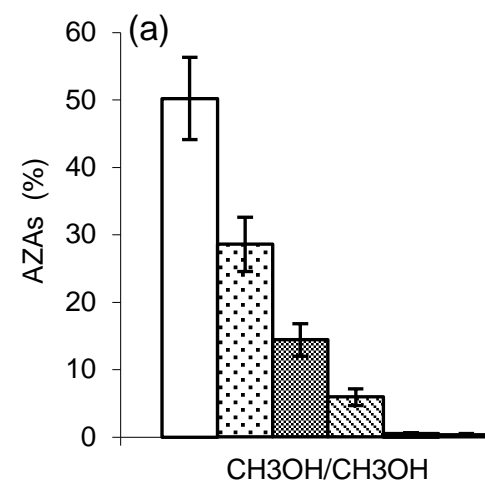

(b)

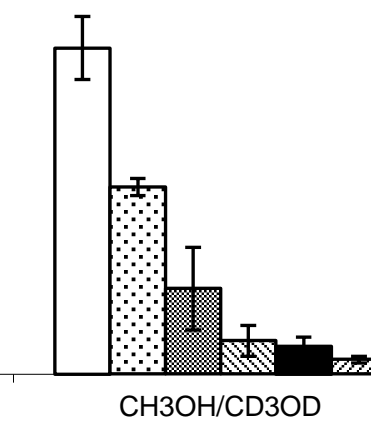

(c)

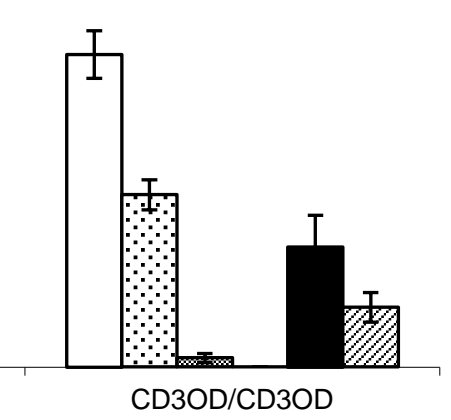

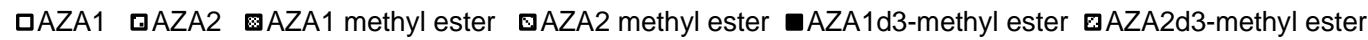

Fig. 3 Percentages of AZA analogues from A. spinosum using centrifugation after: (a) extraction and reconstitution with $\mathrm{MeOH}$; (b) extraction with $\mathrm{MeOH}$ and reconstitution with $\mathrm{CD}_{3} \mathrm{OD}$, and; (c) after extraction and reconstitution with $\mathrm{CD}_{3} \mathrm{OD}$ 

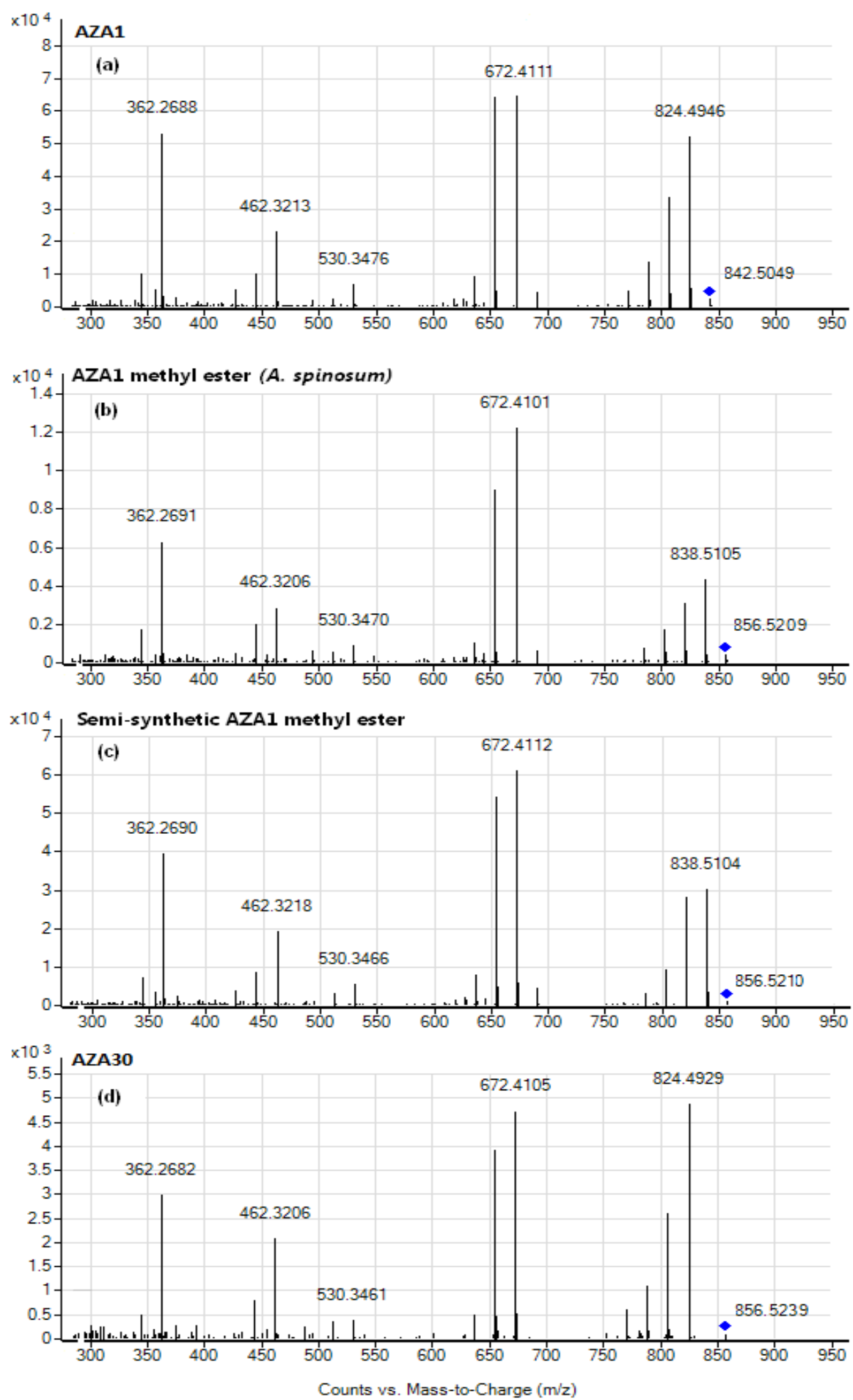

Fig. 4 High resolution mass spectra of: (a) AZA1; (b) AZA1 methyl ester of AZA1 obtained through extraction from A. spinosum; (c) semi-synthetic AZA1 methyl ester, and; (d) AZA30 (AZA1 methyl ketal) obtained as an artefact of storage of AZA1 in $\mathrm{MeOH}$ 


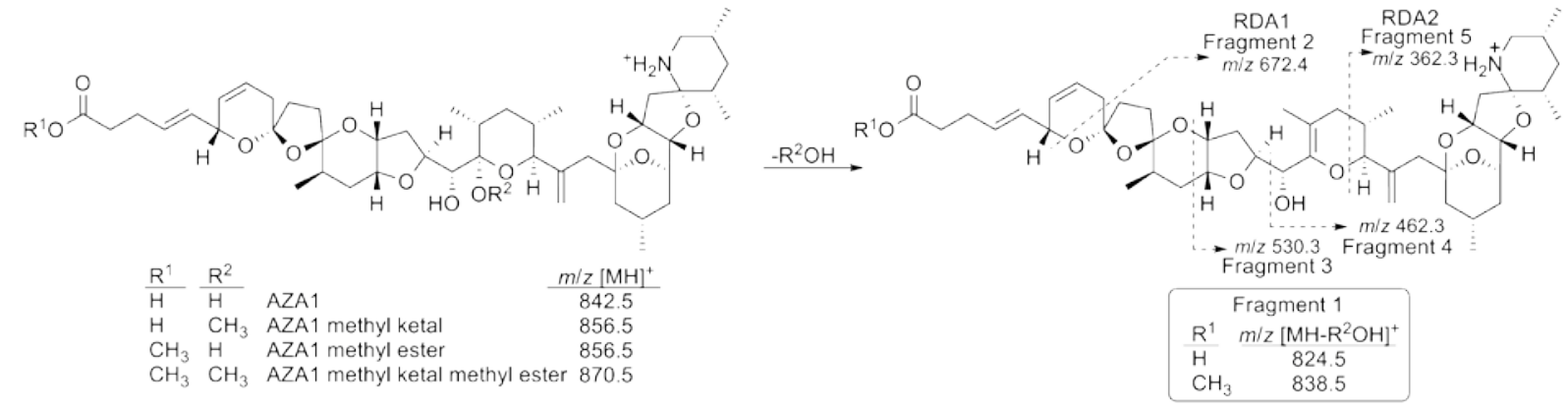

Fig. 5 Structure and $\mathrm{m} / \mathrm{z}$ for $\left[\mathrm{M}+\mathrm{H}^{+}\right.$ions of AZA1, AZA1 methyl ketal, AZA1 methyl ester, AZA1 bismethyl ketal ester and MS/MS fragmentation with indicated groups 

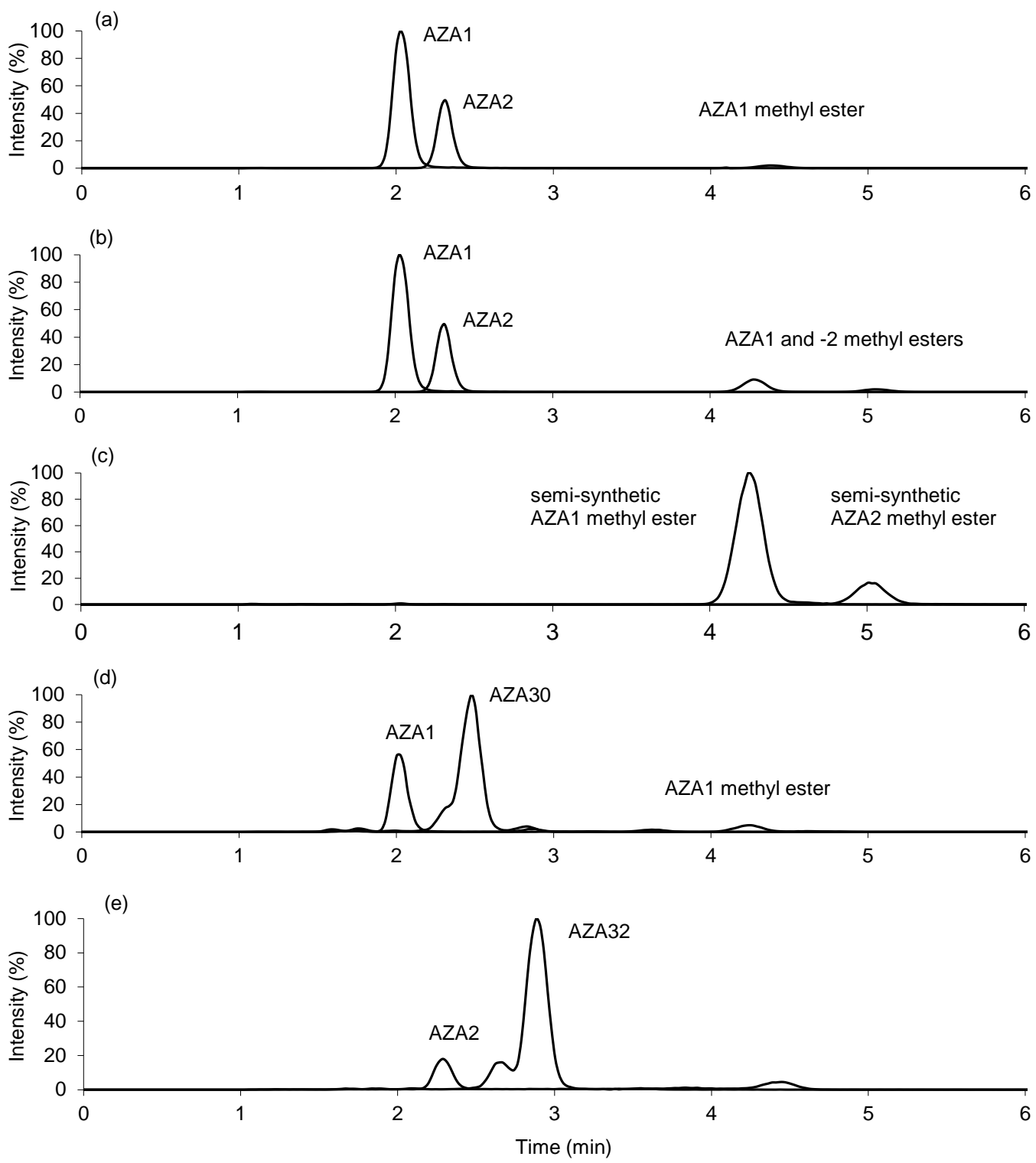

Fig. 6 LC-MS chromatograms of AZAs obtained with an isocratic elution: (a) A. spinosum after extraction with acetone; (b) A. spinosum after extraction with $\mathrm{MeOH}$; (c) semi-synthetic AZA1 and AZA2 methyl esters produced with diazomethane; (d) AZA1 standard after long-term storage in $\mathrm{MeOH}$, and; (e) AZA2 standard after long-term storage in $\mathrm{MeOH}$ 


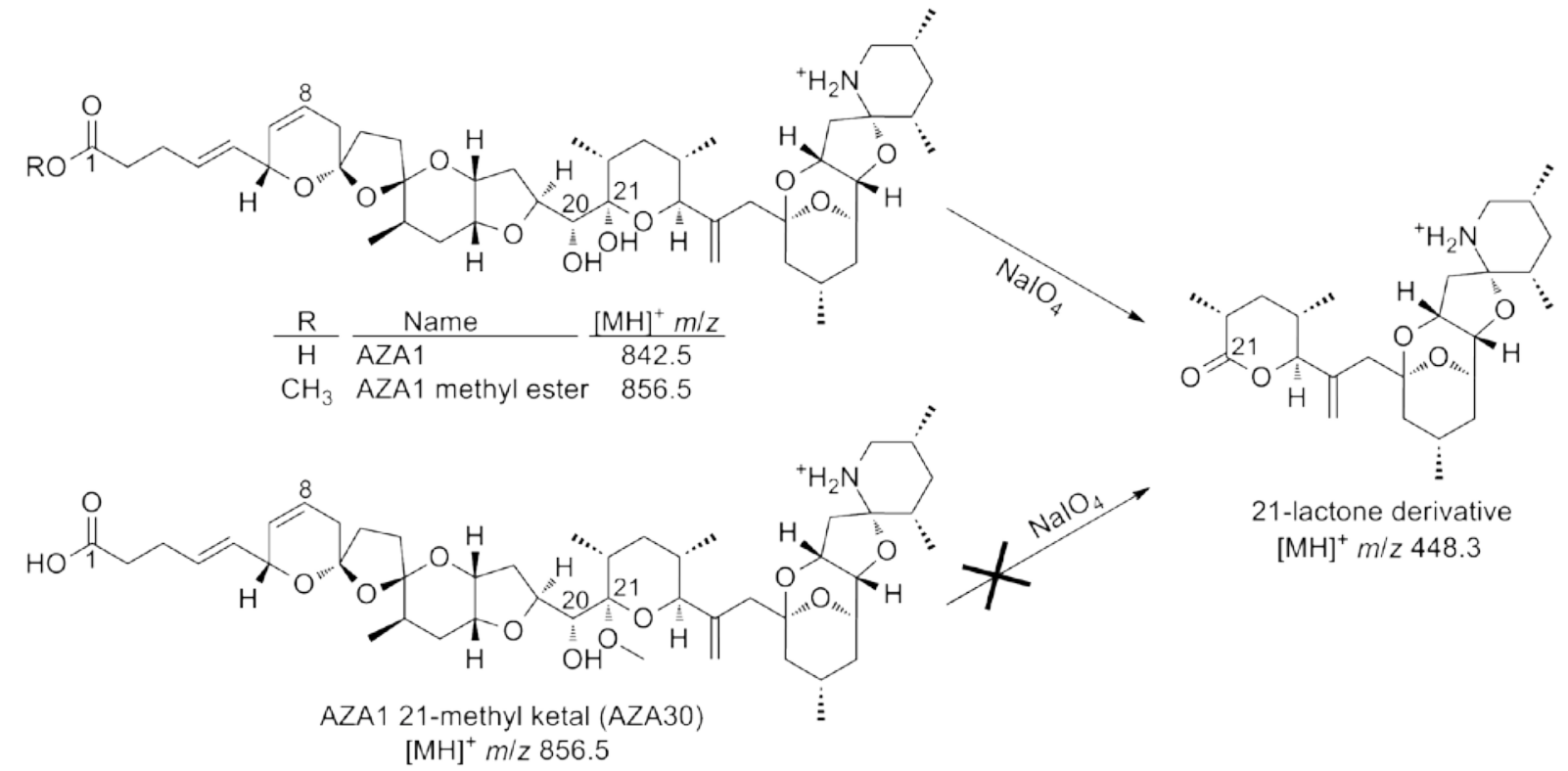

Fig. 7 Fate of AZA1 and its methylated derivatives when treated with sodium periodate, which oxidatively cleaves the 20,21-diol group present in natural AZAs. 

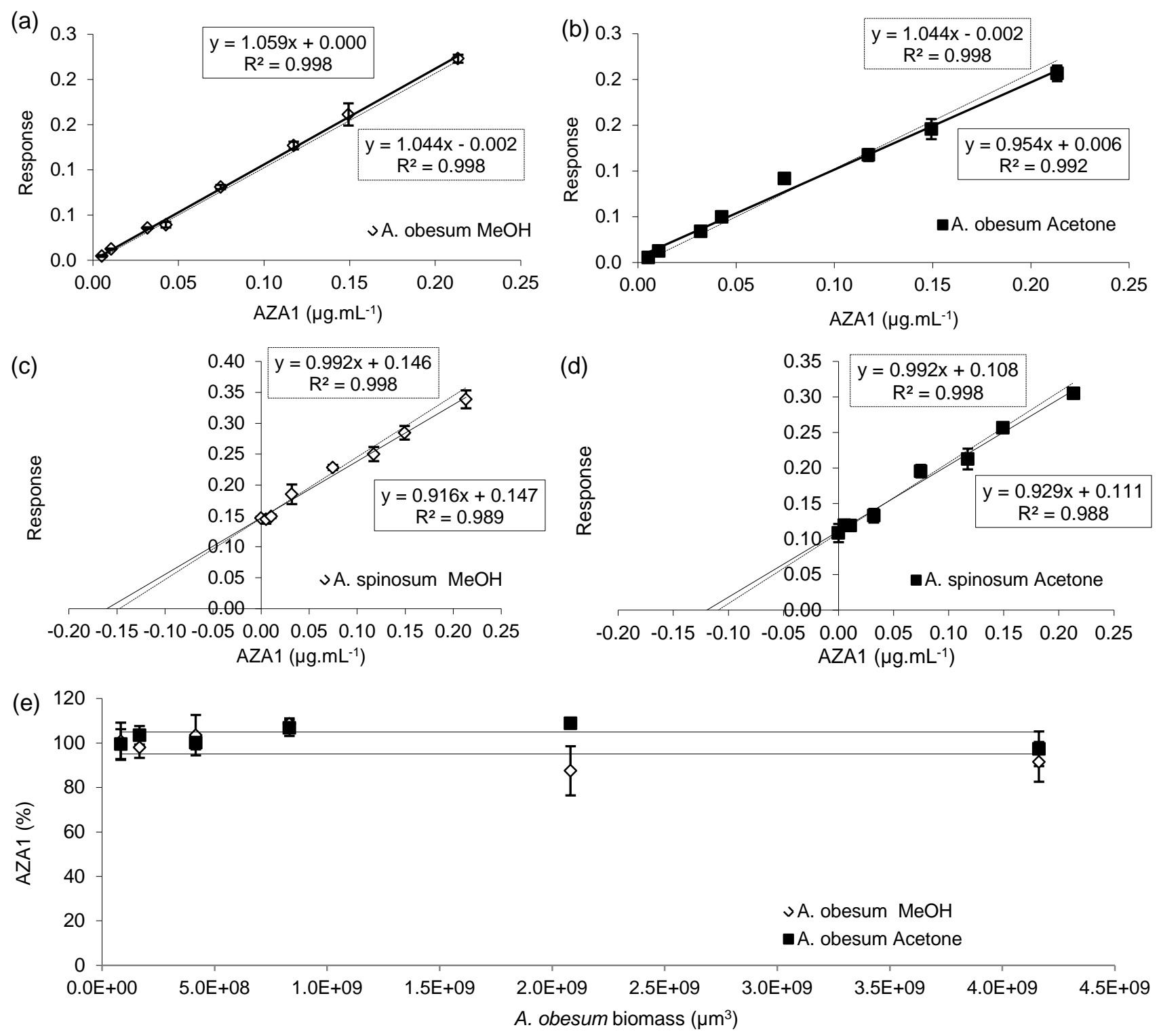

Fig. 8 Slopes, intercepts, correlation coefficients for quantitation of AZA1 in methanolic or acetone extracts of $A$. obesum and $A$. spinosum spiked with standards (a, b, c, d) and as a function of the sample size (e) using LC-MS/MS with isocratic elution. Lines represent the least-squares correlation for quadruplicate injections of spiked matrix-free solutions (a, b, c, d) (dashed lines) and triplicate injection of spiked solutions with matrix (a, b, c, d) (solid lines). The solid lines in (e) represent the 95\% confidence interval obtained from triplicate injection of spiked matrix-free $\mathrm{MeOH}$ solutions. (notice initial response difference between (c) and (d) was due to different sampling day) 


\begin{tabular}{lcc} 
Operating conditions & API 2000 & API 4000 Q-trap \\
\hline Curtain gas & $19 \mathrm{AU}$ & $30 \mathrm{AU}$ \\
Temperature & $350^{\circ} \mathrm{C}$ & $450^{\circ} \mathrm{C}$ \\
Gas 1 & $30 \mathrm{AU}$ & $50 \mathrm{AU}$ \\
Gas 2 & $50 \mathrm{AU}$ & $50 \mathrm{AU}$ \\
CAD gas & $5 \mathrm{AU}$ & Medium \\
lon spray voltage & $5800 \mathrm{~V}$ & $5500 \mathrm{~V}$ \\
Declustering potential & $140 \mathrm{~V}$ & $116 \mathrm{~V}$ \\
Entrance potential & $10 \mathrm{~V}$ & $10 \mathrm{~V}$ \\
Collision cell & $50 \& 70 \mathrm{~V}$ & $41 \& 69 \mathrm{~V}$ \\
Cell exit potential & $35 \mathrm{~V}$ & $12 \& 16 \mathrm{~V}$ \\
\hline
\end{tabular}

Table 1 Operating conditions for the two mass spectrometers ( $\mathrm{AU}=$ arbitrary units)

\begin{tabular}{lcccc}
\hline & AZA1 (\%) & AZA2 (\%) & $\begin{array}{c}\text { AZA1 } \\
\text { methyl ester } \\
(\%)\end{array}$ & $\begin{array}{c}\text { AZA2 } \\
\text { methyl ester } \\
(\%)\end{array}$ \\
\hline Filtration \& MeOH & 49 & 18 & 31 & 3 \\
Centrifugation \& MeOH & 71 & 26 & 3 & 0 \\
Filtration \& Acetone & 55 & 20 & 23 & 2 \\
Centrifugation \& Acetone & 73 & 25 & 2 & 0 \\
\hline
\end{tabular}

Table 2 Percentage of AZA analogue as a function of the harvesting (filtration or centrifugation) and extraction ( $\mathrm{MeOH}$ or acetone) procedure for 3 consecutive extraction cycles

\begin{tabular}{ccccc}
\hline Solvent & AZA1 & AZA2 & $\begin{array}{c}\text { AZA1 methyl } \\
\text { ester }\end{array}$ & Total \\
\hline MeOH & $85 \pm 8$ & $25 \pm 2$ & $3.7 \pm 0.3($ d $)$ & $114 \pm 10$ \\
Acetone & $87 \pm 5$ & $24 \pm 1$ & $2.4 \pm 0.3(\mathrm{c})$ & $113 \pm 6$ \\
MeCN & $95 \pm 5$ & $26 \pm 1$ & $0.8 \pm 0.1(\mathrm{~b})$ & $122 \pm 7$ \\
EtOH & $94 \pm 10$ & $26 \pm 2$ & $3.7 \pm 0.2(\mathrm{~d})$ & $124 \pm 11$ \\
$\mathrm{DCM}$ & $82 \pm 2$ & $22 \pm 1$ & $0.3 \pm 0.1(\mathrm{a})$ & $104 \pm 3$ \\
\hline
\end{tabular}

Table 3 Yield of AZA (fg.cell ${ }^{-1}$ ) with extraction solvent from $A$. spinosum pellets after centrifugation. Values with different letters are statistically different at $\mathrm{P}<0.05$ 


\begin{tabular}{|c|c|c|c|c|c|}
\hline Ion & & AZA1 & $\begin{array}{l}\text { AZA1 methyl } \\
\text { ester (artefact) }\end{array}$ & $\begin{array}{l}\text { AZA1 methyl } \\
\text { ester (semi- } \\
\text { synthetic) } \\
\end{array}$ & AZA30 \\
\hline \multirow[t]{2}{*}[\mathrm{MH}]{$^{+}$} & Formula & $\mathrm{C}_{47} \mathrm{H}_{72} \mathrm{NO}_{12}^{+}$ & $\mathrm{C}_{48} \mathrm{H}_{74} \mathrm{NO}_{12}^{+}$ & $\mathrm{C}_{48} \mathrm{H}_{74} \mathrm{NO}_{12}{ }^{+}$ & $\mathrm{C}_{48} \mathrm{H}_{74} \mathrm{NO}_{12}{ }^{+}$ \\
\hline & $m / z(\Delta)$ & $842.5049(0.0)$ & $856.5209(0.5)$ & $856.5210(0.6)$ & $\begin{array}{c}856.5239 \\
(4.0)\end{array}$ \\
\hline \multirow{2}{*}{$\begin{array}{l}{[\mathrm{MH}-\mathrm{ROH}]^{+}} \\
\text {(Fragment } \\
\text { 1) }\end{array}$} & Formula & $\mathrm{C}_{47} \mathrm{H}_{70} \mathrm{NO}_{11}^{+}$ & $\mathrm{C}_{48} \mathrm{H}_{72} \mathrm{NO}_{11}{ }^{+}$ & $\mathrm{C}_{48} \mathrm{H}_{72} \mathrm{NO}_{11}^{+}$ & $\mathrm{C}_{47} \mathrm{H}_{70} \mathrm{NO}_{11}{ }^{+}$ \\
\hline & $m / z(\Delta)$ & $824.4946(0.4)$ & $838.5105(0.6)$ & $838.5104(0.5)$ & $\begin{array}{c}824.4929 \\
(1.7)\end{array}$ \\
\hline \multirow{2}{*}{$\begin{array}{l}\text { Fragment } 2 \\
\text { (RDA 1) }\end{array}$} & Formula & $\mathrm{C}_{38} \mathrm{H}_{58} \mathrm{NO}_{9}{ }^{+}$ & $\mathrm{C}_{38} \mathrm{H}_{58} \mathrm{NO}_{9}^{+}$ & $\mathrm{C}_{38} \mathrm{H}_{58} \mathrm{NO}_{9}^{+}$ & $\mathrm{C}_{38} \mathrm{H}_{58} \mathrm{NO}_{9}^{+}$ \\
\hline & $m / z(\Delta)$ & $672.4111(0.7)$ & $672.4101(0.7)$ & $672.4112(0.9)$ & $\begin{array}{c}672.4105 \\
(0.2)\end{array}$ \\
\hline \multirow[t]{2}{*}{ Fragment 3} & Formula & $\mathrm{C}_{31} \mathrm{H}_{48} \mathrm{NO}_{6}^{+}$ & $\mathrm{C}_{31} \mathrm{H}_{48} \mathrm{NO}_{6}{ }^{+}$ & $\mathrm{C}_{31} \mathrm{H}_{48} \mathrm{NO}_{6}^{+}$ & $\mathrm{C}_{31} \mathrm{H}_{48} \mathrm{NO}_{6}^{+}$ \\
\hline & $m / z(\Delta)$ & $530.3476(0.0)$ & $530.3470(1.1)$ & 530.3466 (1.9) & $\begin{array}{c}530.3461 \\
(2.8)\end{array}$ \\
\hline \multirow[t]{2}{*}{ Fragment 4} & Formula & $\mathrm{C}_{27} \mathrm{H}_{44} \mathrm{NO}_{5}{ }^{+}$ & $\mathrm{C}_{27} \mathrm{H}_{44} \mathrm{NO}_{5}^{+}$ & $\mathrm{C}_{27} \mathrm{H}_{44} \mathrm{NO}_{5}^{+}$ & $\mathrm{C}_{27} \mathrm{H}_{44} \mathrm{NO}_{5}{ }^{+}$ \\
\hline & $m / z(\Delta)$ & $462.3213(0.2)$ & 462.3206 (1.7) & $462.3218(0.9)$ & $\begin{array}{c}462.3206 \\
(1.7)\end{array}$ \\
\hline \multirow{2}{*}{$\begin{array}{l}\text { Fragment } 5 \\
\text { (RDA 2) }\end{array}$} & Formula & $\mathrm{C}_{22} \mathrm{H}_{36} \mathrm{NO}_{3}^{+}$ & $\mathrm{C}_{22} \mathrm{H}_{36} \mathrm{NO}_{3}{ }^{+}$ & $\mathrm{C}_{22} \mathrm{H}_{36} \mathrm{NO}_{3}^{+}$ & $\mathrm{C}_{22} \mathrm{H}_{36} \mathrm{NO}_{3}^{+}$ \\
\hline & $m / z(\Delta)$ & $362.2688(0.6)$ & $362.2691(0.3)$ & $362.2690(0.0)$ & $\begin{array}{c}362.2682 \\
(2.2)\end{array}$ \\
\hline
\end{tabular}

Table 4 High resolution LC-MS and LC-MS/MS data (measured $m / z$ and $\Delta(\mathrm{ppm})$ ) for AZA1, its methyl ester (extraction artefact from $A$. spinosum, and semi-synthetic), and AZA30 (AZA1 methyl ketal). Fragment ions correspond to Fig. 1 

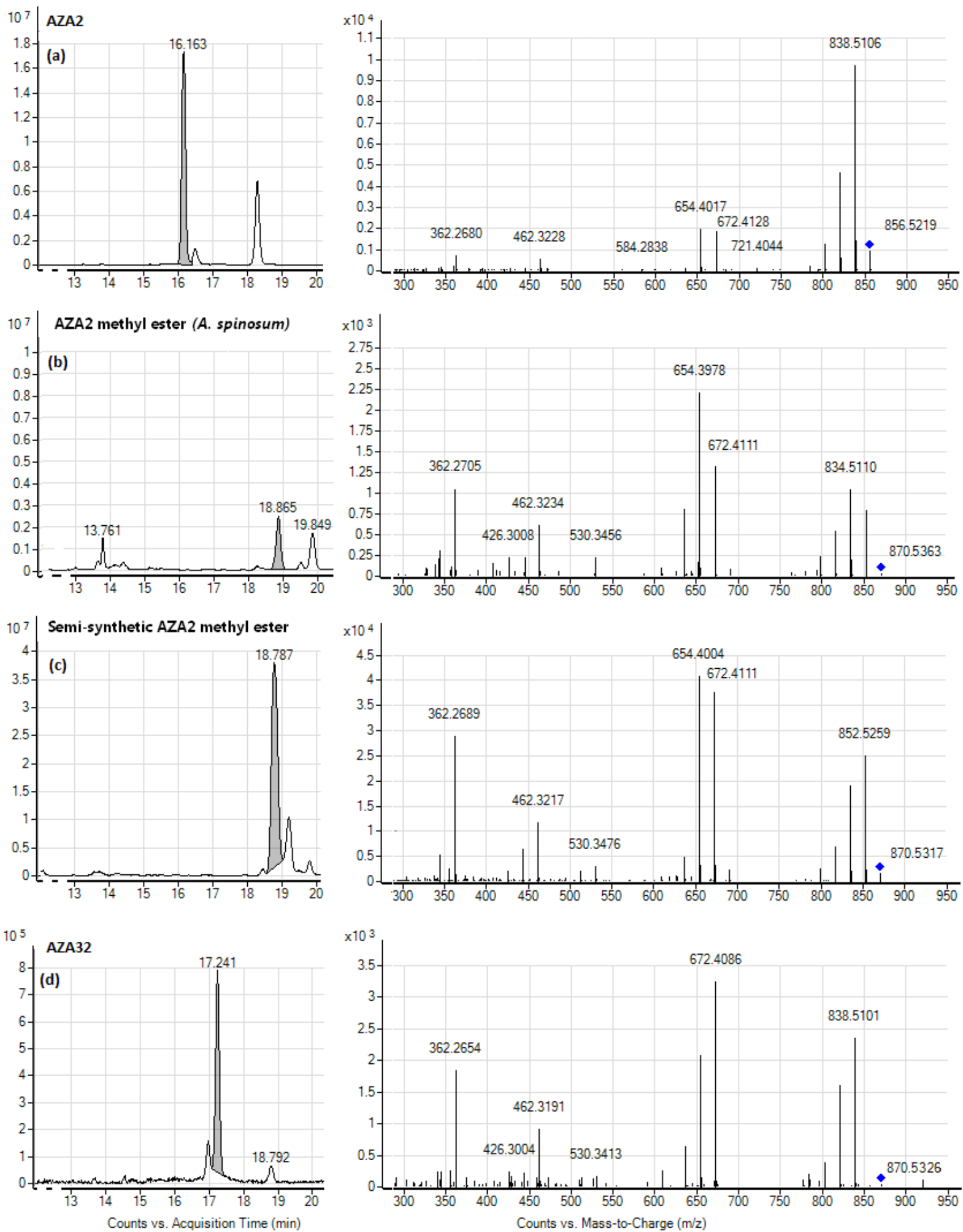

Fig. S1 LC-MS chromatograms and targeted high resolution MS/MS spectra, obtained with an Agilent 6540 QTOF, for AZA2 and derivatives: (a) AZA2; (b) AZA2 methyl ester in an A. spinosum extract; (c) semi-synthetic AZA2 methyl ester produced from AZA2 via derivatization with diazomethane, and; (d) AZA32 obtained from long-term storage of AZA2 in $\mathrm{MeOH}$ 


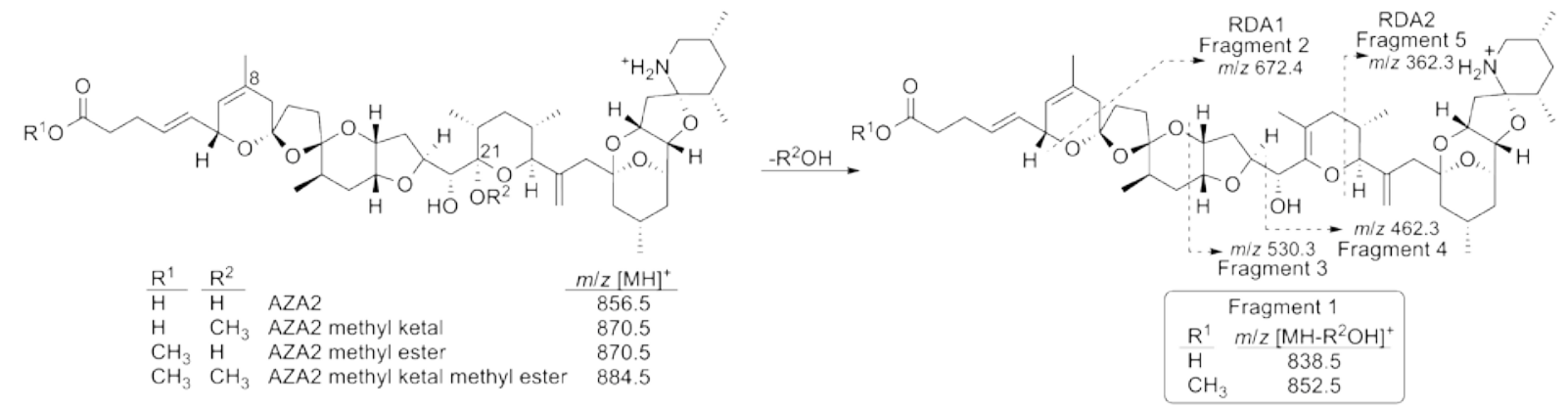

Fig. S2 Structure and $m / z$ for $[M+H]^{+}$ions of AZA2, AZA2 methyl ketal, AZA2 methyl ester, AZA2 bismethyl ketal ester and MS/MS fragmentation with indicated groups 
Table S3 High resolution LC-MS and LC-MS/MS data (measured $\mathrm{m} / \mathrm{z}$ and $\Delta$ (ppm)) for AZA2, its methyl ester (extraction artefact from A. spinosum, and semi-synthetic), and AZA32 (AZA2 methyl ketal). Fragment ions correspond to Fig. S2

\begin{tabular}{|c|c|c|c|c|c|}
\hline Ion & & AZA2 & $\begin{array}{l}\text { AZA2 methyl ester } \\
\text { (artefact) }\end{array}$ & $\begin{array}{l}\text { AZA2 methyl ester } \\
\text { (semi-synthetic) }\end{array}$ & AZA32 \\
\hline \multirow[t]{2}{*}[\mathrm{MH}]{$^{+}$} & Formula & $\mathrm{C}_{48} \mathrm{H}_{74} \mathrm{NO}_{12}{ }^{+}$ & $\mathrm{C}_{49} \mathrm{H}_{76} \mathrm{NO}_{12}^{+}$ & $\mathrm{C}_{49} \mathrm{H}_{76} \mathrm{NO}_{12}^{+}$ & $\mathrm{C}_{49} \mathrm{H}_{76} \mathrm{NO}_{12}{ }^{+}$ \\
\hline & $m / z(\Delta)$ & 856.5219 (1.57) & $870.5363(0.11)$ & 870.5317 (5.17) & $870.5326(4.14)$ \\
\hline \multirow{2}{*}{$\begin{array}{l}{[\mathrm{MH}-\mathrm{ROH}]^{+}} \\
\text {(Fragment } 1 \text { ) }^{\text {Fragment }}\end{array}$} & Formula & $\mathrm{C}_{48} \mathrm{H}_{71} \mathrm{NO}_{11}^{+}$ & $\mathrm{C}_{49} \mathrm{H}_{73} \mathrm{NO}_{12}^{+}$ & $\mathrm{C}_{49} \mathrm{H}_{73} \mathrm{NO}_{12}^{+}$ & $\mathrm{C}_{48} \mathrm{H}_{72} \mathrm{NO}_{11}^{+}$ \\
\hline & $m / z(\Delta)$ & $838.5106(0.72)$ & 852.5241 (1.81) & $852.5241(0.3)$ & $838.5101(0.12)$ \\
\hline \multirow{2}{*}{$\begin{array}{l}\text { Fragment } 2 \\
\text { (RDA 1) }\end{array}$} & Formula & $\mathrm{C}_{38} \mathrm{H}_{59} \mathrm{NO}_{9}^{+}$ & $\mathrm{C}_{38} \mathrm{H}_{59} \mathrm{NO}_{9}^{+}$ & $\mathrm{C}_{38} \mathrm{H}_{59} \mathrm{NO}_{9}{ }^{+}$ & $\mathrm{C}_{38} \mathrm{H}_{59} \mathrm{NO}_{9}^{+}$ \\
\hline & $m / z(\Delta)$ & $672.4128(3.27)$ & $672.4111(0.74)$ & $672.4111(0.74)$ & 672.4086 (2.97) \\
\hline \multirow[t]{2}{*}{ Fragment 3* } & Formula & $\mathrm{C}_{31} \mathrm{H}_{49} \mathrm{NO}_{6}^{+}$ & $\mathrm{C}_{31} \mathrm{H}_{49} \mathrm{NO}_{6}^{+}$ & $\mathrm{C}_{31} \mathrm{H}_{49} \mathrm{NO}_{6}^{+}$ & $\mathrm{C}_{31} \mathrm{H}_{49} \mathrm{NO}_{6}^{+}$ \\
\hline & $m / z(\Delta)$ & 530.3419 (10.8) & 530.3456 (3.77) & $530.3476(0.00)$ & $530.3413(11.9)$ \\
\hline \multirow[t]{2}{*}{ Fragment 4} & Formula & $\mathrm{C}_{27} \mathrm{H}_{45} \mathrm{NO}_{5}^{+}$ & $\mathrm{C}_{27} \mathrm{H}_{45} \mathrm{NO}_{5}^{+}$ & $\mathrm{C}_{27} \mathrm{H}_{45} \mathrm{NO}_{5}^{+}$ & $\mathrm{C}_{27} \mathrm{H}_{45} \mathrm{NO}_{5}^{+}$ \\
\hline & $m / z(\Delta)$ & $462.3228(3.03)$ & 462.3234 (4.33) & $462.3217(0.65)$ & 462.3191 (4.97) \\
\hline \multirow{2}{*}{$\begin{array}{l}\text { Fragment } 5 \\
\text { (RDA 2) }\end{array}$} & Formula & $\mathrm{C}_{22} \mathrm{H}_{37} \mathrm{NO}_{3}^{+}$ & $\mathrm{C}_{22} \mathrm{H}_{37} \mathrm{NO}_{3}^{+}$ & $\mathrm{C}_{22} \mathrm{H}_{37} \mathrm{NO}_{3}{ }^{+}$ & $\mathrm{C}_{22} \mathrm{H}_{37} \mathrm{NO}_{3}^{+}$ \\
\hline & $m / z(\Delta)$ & $362.2680(2.76)$ & 362.2705 (4.14) & $362.2689(0.28)$ & 362.2654 (9.94) \\
\hline
\end{tabular}

*The abundance of the 530 ion was very low, explaining the somewhat higher mass errors for this group 


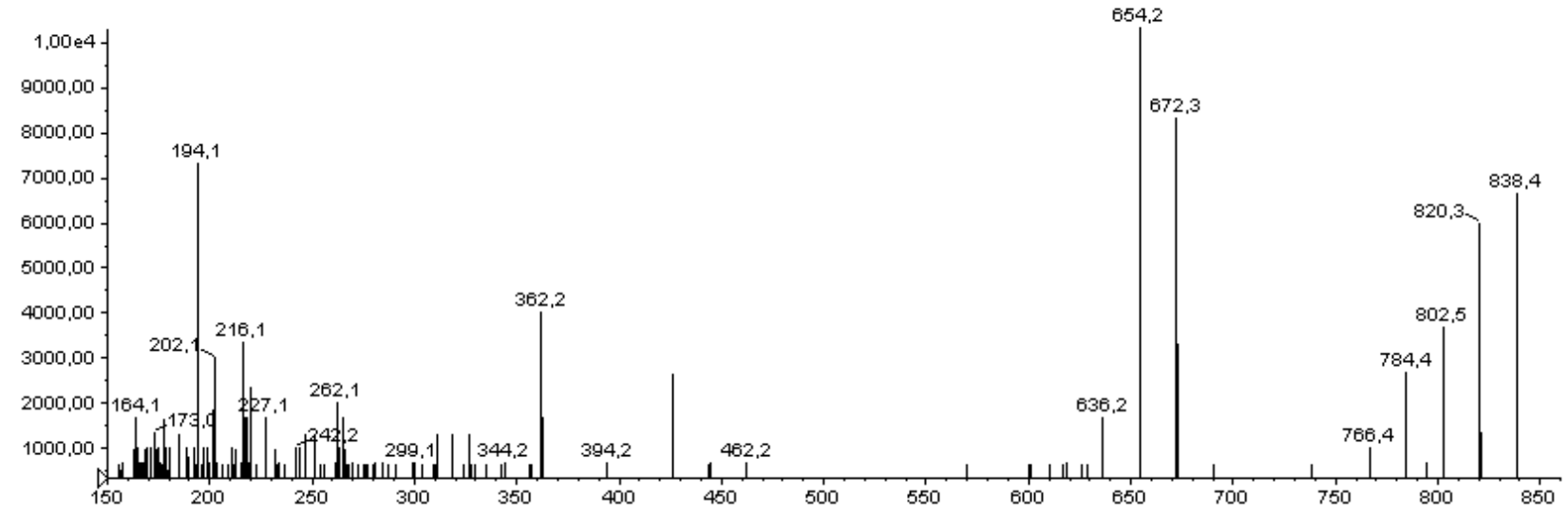

Fig. S3 AZA1 methyl ester spectrum previously reported by Krock et al. obtained through extraction of A. spinosum and analysed with an API4000 Qtrap (CUR: 10 psi, CAD: Medium, IS: 5500 V, TEM: 0, GS1: 10, GS2: 0, DP: 100, CES: 0, CE: 70 V) 

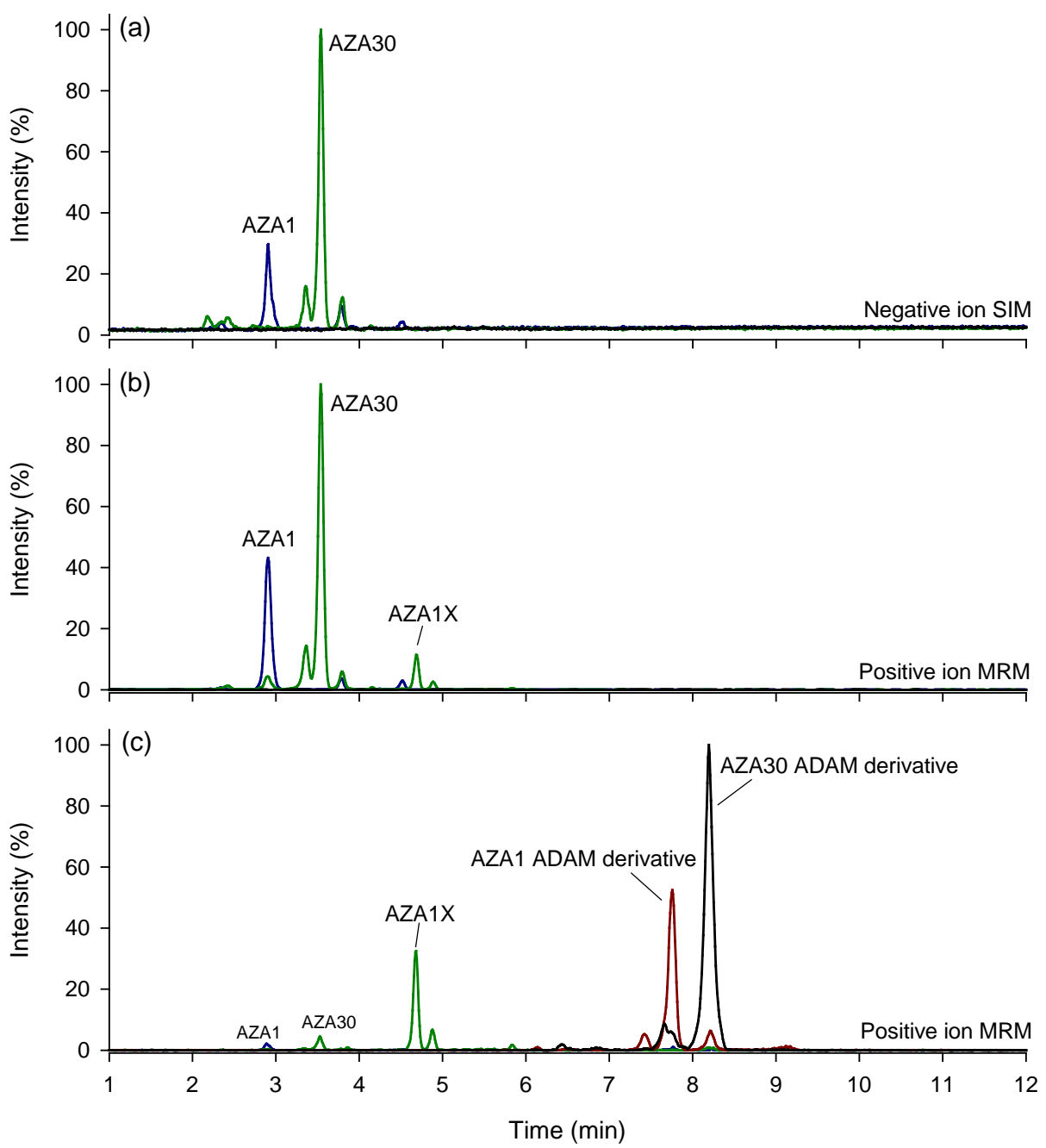

Fig. S4 Gradient elution LC-MS(/MS) analysis of a sample containing AZA1, AZA30 and AZA1 methyl ester: (a) negative ion SIM mode $\left([\mathrm{M}-\mathrm{H}]^{-}\right.$of $\left.840.5,854.5,868.5\right)$ showing $A Z A 1$ and $A Z 30$, while AZA1 methyl ester is not detected; (b) positive ion MRM mode $\left([\mathrm{M}+\mathrm{H}]^{+}\right.$of $842 \rightarrow 672,856 \rightarrow 672$, $1032 \rightarrow 672,1046 \rightarrow 672$ ) showing AZA1, AZA30 and AZA1 methyl ester (AZA1X), and; (c) the same sample following ADAM derivatization, showing successful derivatization of AZA1 and AZA30 as their (9-anthryl)methyl esters, whereas AZA1 methyl ester is unaffected (because it is already esterified, and so is unable to react) 


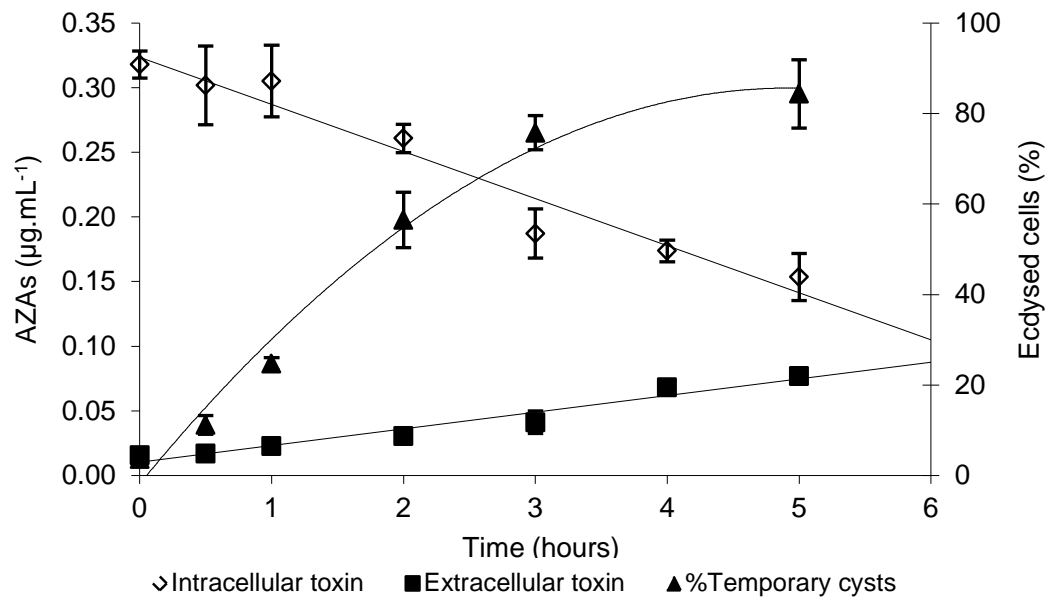

Fig. S5 Effect of residence time in a sampling tube on A. spinosum, prior to extraction, on the measured intracellular and extracellular azaspiracid content 


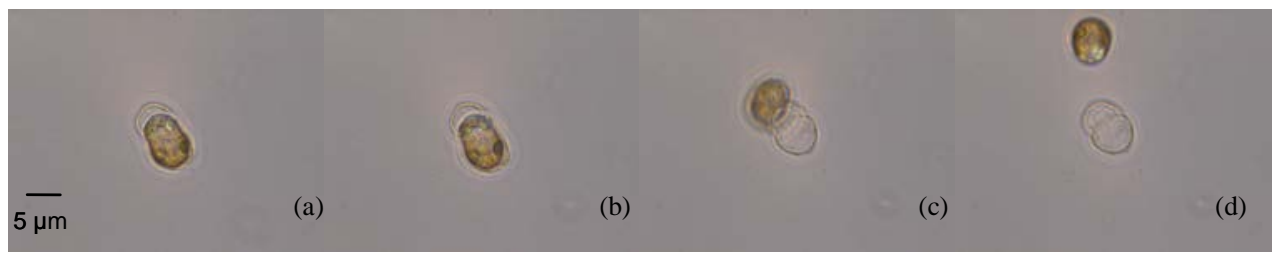

Fig. S6 a-d Different phases of $A$. spinosum dehiscence, b-c, protoplast extrusion from the theca 